\title{
Guía clínica para el diagnóstico y cuidado de niños/adolescentes con bronquiolitis obliterante post-infecciosa, 2009
}

\author{
LUIS E. VEGA-BRICEÑO, DANIEL ZENTENO A. y COMISIÓN MULTIDISCIPLINARIA \\ PARA EL ESTUDIO DE LA BRONQUIOLITIS OBLITERANTE*; SOCIEDAD CHILENA DE NEUMOLOGÍA \\ PEDIÁTRICA Y SOCIEDAD CHILENA DE ENFERMEDADES RESPIRATORIAS
}

\section{Clinical guide for diagnosis and care of children and adolescents with post-infectious bronchiolitis obliterans, 2009}

Bronchiolitis obliterans in children is an infrequent clinical syndrome, characterized by chronic airflow obstruction associated to inflammatory changes and different degrees of fibrosis in the small airways. Etiologies are varied but the most frequent one is the association with viral infections, mainly adenovirus. There is no consensus regarding diagnostic criteria, but a spectrum of persistent symptoms together with a mosaic pattern, bronchiectasis and persistent atelectasis is considered useful. Pulmonary biopsy has been questioned because of its low yield, invasiveness and complications. No specific treatment is available, therefore its treatment is supportive. Probably the best strategy is the aggressive use of antibiotics, constant kinesic and nutritional support and early pulmonary rehabilitation. This clinical guide represents a multidisciplinary effort, based on current evidence, to provide practical tools for the diagnosis and care of children and adolescents affected by postinfectious bronchiolitis obliterans

Key words: Clinical guides, bronchiolitis obliterans, diagnosis, treatment, children, adolescents.

\section{Resumen}

La bronquiolitis obliterante (BO) es un síndrome clínico poco frecuente en niños, caracterizado por la obstrucción crónica al flujo de aire asociado a cambios inflamatorios y distintos grados de fibrosis en la vía aérea pequeña. Si bien existen muchas etiologías, la causa más frecuente se asocia a infecciones respiratorias virales, principalmente adenovirus. No existe un consenso para establecer su diagnóstico; sin embargo, se considera un espectro de síntomas persistentes asociados a un patrón en mosaico, bronquiectasias y atelectasias persistentes. El papel de la biopsia pulmonar ha sido cuestionado por su bajo rendimiento, invasividad y complicaciones. No existe un tratamiento específico por lo que el manejo es soporte. Probablemente la mejor estrategia constituya el empleo de antibióticos en forma agresiva, soporte kinésico y nutricional constante y una precoz rehabilitación pulmonar. Estas guías clínicas representan un esfuerzo multidisciplinario, basado en evidencias actuales para brindar herramientas prácticas para el diagnóstico y cuidado de niños y adolescentes con BO post infecciosa.

Palabras clave: Guías clínicas, bronquiolitis obliterante, diagnóstico, tratamiento, niños, adolescentes.

* Médicos: Selim Abara, Cecilia Álvarez, Juan Carlos Arancibia, José Domingo Arce, Salesa Barja, Pablo Bertrand, Lina Boza, Carolina Campos, José A. Castro-Rodríguez, Solange Caussade, Bernardita Chateau, Ilse Contreras, Fabiola Durán, Tatiana Espinosa, Patricia Fernández, Oscar Fielbaum, Marianela García, Ramiro González, Jury Hernández, Patricio Herrera, Fernando Iñiguez, Leticia Jakubson, Ricardo Kogan, Andres Koppmann, Isabel Largo, Viviana Lezana, Marcela Linares, Soledad Montes, Constanza Muñoz, Rebeca Paiva, Genoveva Parra, María Angélica Pérez, José A. Perillán, Francisco Prado, Ignacio Sánchez, Junia Silva, Alexis Strickler, Isabel Valdez, Adriana Wegner, María Elena Wevar, Alejandra Zamorano, Sergio Zúñiga. Enfermeras: Claudia Rodríguez, Alejandra Rosales, Pamela Salinas. Kinesiólogos: Daniel Ciudad, Stefanie Contreras, Rodolfo Meyer, Homero Puppo, Richard Silva, Roberto Vera, Gregory Villarroel. Servicio social y psicología: María Cristina Canales, Margaret Castro. 


\section{Introducción}

El incremento en la sobrevida de muchos pacientes con enfermedades pulmonares crónicas (EPC) ha traído consigo la aparición de complicaciones, tanto respiratorias como no respiratorias, que acompañan a niños cada vez más complejos y que representan un continuo desafío. Los pacientes con EPC exhiben diversos cambios inflamatorios desde el inicio de la injuria, los cuales persisten hasta el desarrollo -muchas veces inevitable- de cicatrices y/o fibrosis pulmonar; más aún, diversos patógenos pueden colonizar la vía aérea y participar de la progresión de este daño inicial. Hoy, contamos con nuevas herramientas diagnósticas; pese a ello, las opciones terapéuticas son reducidas y el éxito del manejo clínico dependerá muchas veces de la oportuna intervención antibiótica, una constante kinesioterapia respiratoria y el inicio de una adecuada y precoz rehabilitación pulmonar en la mayoría.

La bronquiolitis obliterante (BO) es una condición respiratoria poco frecuente, de un amplio y variado espectro clínico, responsable de la obstrucción y/u obliteración de la vía aérea pequeña. La BO está asociada a una variedad de antecedentes clínicos (Ej. trasplante, infecciones, intoxicaciones) que por sí mismos pueden producir este complejo síndrome clínico; aunque se reconoce su existencia desde hace muchos años, no existe consenso para establecer su diagnóstico. Establecer su existencia requiere de la combinación de diversos instrumentos: clínicos, laboratorio de función pulmonar, imágenes y eventualmente, histológicos cuando exista una duda razonable.

El propósito de este documento es delinear una guía clínica para el diagnóstico y cuidado estandarizado de niños y adolescentes con BO post-infecciosa. Este documento de carácter inédito, debe ser usado solamente como una aproximación clínica de referencia. La Sociedad Chilena de Neumología Pediátrica (SOCHINEP) y la Sociedad Chilena de Enfermedades Respiratorias (SER) han trabajo para la elaboración de este documento que representa el primer esfuerzo multidisciplinario en nuestro medio y Latinoamérica para unificar esfuerzos de neumólogos, pediatras, enfermeras, kinesiólogos, psicólogos y trabajadora social en torno a BO. Ya que mucha de la información publicada es en población adulta (especialmente post-trasplante o asociada a neumonía en organización); es importante resaltar que la elaboración de estas guías está preferentemente situada en el escenario pediátrico.

\section{Estableciendo el diagnóstico}

\section{Aspectos clínicos}

El término $\mathrm{BO}$ es un concepto amplio, que traduce un síndrome clínico poco frecuente, caracterizado por obstrucción crónica al flujo de aire asociado a cambios inflamatorios asociados a fibrosis en la vía aérea (VA) pequeña. Existen muchas etiologías asociadas; sin embargo, la causa más frecuente son las secuelas asociadas a infecciosas respiratorias virales. El diagnóstico de BO está basado sobre la evidencia clínica y radiológica: persistencia de tos y sibilancias, asociadas a retracciones, crépitos (crujidos) y anormalidades en la radiografía de tórax por meses o años. Algunos pacientes con $\mathrm{BO}$ tienen dependencia de oxígeno $\left(\mathrm{O}_{2}\right)$. Para efectos de esta guía se considera sugerente de BO (diagnóstico operacional) a:

1. Persistencia de síntomas respiratorios: tos, disnea, sibilancias, crépitos (crujidos) y/o hipoxemia, definida como saturación arterial de $\mathrm{O}_{2}\left(\mathrm{SpO}_{2}\right)<93 \%$; 4-6 semanas post-injuria (indispensable).

2. Atrapamiento de aire, patrón en mosaico, fibrosis, y/o bronquiectasias en la tomografía de alta resolución (HRCT) al menos 6 semanas post-injuria (indispensable).

3. Exclusión de: Asma, fibrosis quística (FQ), displasia broncopulmonar (DBP), tuberculosis (TBC) pulmonar, disquinesia ciliar primaria, deficiencia de $\alpha 1$-antitripsina, cardiopatía congénita (indispensable).

4. Ausencia o escasa respuesta clínica y/o en flujos espiratorios forzados a salbutamol $400 \mu \mathrm{g}$ por MDI (no indispensable).

5. Aislamiento de adenovirus en secreciones respiratorias durante una fase aguda de comportamiento grave.

6. No respuesta clínica y/o en flujos espiratorios forzados disminuidos luego de 2-4 semanas de prednisona (1-2 $\mathrm{mg} / \mathrm{kg} /$ día) (sugerente).

7. Flujos espiratorios forzados $\left(\mathrm{FEF}_{25-75} \mathrm{y} / \mathrm{o} \mathrm{VEF}_{1}\right)$ $<40 \%$ predicho para la edad (sugerente).

8. Atrapamiento de aire en la radiografía de tórax al menos 6 semanas post-injuria (sugerente).

No existe un consenso en cuanto al número de criterios necesarios para establecer el diagnóstico. Los 3 primeros criterios son indispensables, aunque puede incluir sólo a las formas más graves. Si bien existe un espectro clínico amplio, éste debe ser discutido -caso a casosegún el criterio de cada centro. 
Tabla 1. Diagnóstico diferencial de BO

- Fibrosis quística

- Asma grave

- Displasia broncopulmonar

- Inmunodeficiencias

- Disquinesia ciliar primaria

- Déficit alfa 1-antitripsina

- Cardiopatía congénita

\section{Injuria}

La etiología relacionada con $\mathrm{BO}$ es muy variada. Incluye injuria epitelial asociada a rechazo de trasplante (pulmón, corazón, médula), infección respiratoria del tracto respiratorio bajo asociado a virus (adenovirus, influenza, parainfluenza, sarampión, VRS), o Mycoplasma pneumoniae, enfermedad del tejido conectivo (especialmente artritis reumatoidea, síndrome de Sjögren), inhalación de humos tóxicos, neumonitis por hipersensibilidad crónica, drogas, Steven-Johnson.

\section{Diagnóstico diferencial}

$\mathrm{BO}$ es un diagnóstico de descarte por lo que siempre se debe estudiar y excluir otras condiciones respiratorias crónicas asociadas a obstrucción persistente de VA pequeña (Tabla 1).

\section{Función pulmonar}

\subsection{Espirometría}

Constituye una herramienta importante para la evaluación y seguimiento de pacientes con BO post infecciosa, contribuyendo a establecer diagnóstico, determinar respuesta broncodilatadora, definir severidad y eventualmente su progresión. Destaca el patrón obstructivo, el cual se asocia a capacidad vital forzada (CVF) disminuida. Existe un reducido número de pacientes que pueden tener respuesta a salbutamol aunque no se alcanza la normalidad en volumen espiratorio forzado en el primer segundo $\left(\mathrm{VEF}_{1}\right)$. Los flujos espiratorios forzados $\left(\mathrm{FEF}_{25-75}\right)$ siempre están muy disminuidos. Un valor $<30 \%$ del teórico podría constituir un marcador precoz y sensible. Existe una exagerada disminución del $\mathrm{FEF}_{25-75}$ en relación a un $\mathrm{VEF}_{1}$ levemente disminuido.

\subsection{Oscilometría de impulso (IOS)}

La IOS mide en forma directa la resistencia total del sistema respiratorio (Rtot o Zrs) espe- cialmente en niños no colaboradores. Existe aumento de la resistencia (R5, R20) en vías periféricas, siendo las resistencias a frecuencias bajas más elevadas que a frecuencias altas: R5 es claramente mayor que R20. Los valores patológicos se observan: $>150 \%$ de los valores predictivos para Zrs, R5 y R20 y para X5 cuando el valor medido es más negativo que el valor predictivo más 0,15 . La IOS permite una medición más precisa y precoz del compromiso de la VA periférica pudiendo demostrar la limitación al flujo aéreo durante respiración tranquila y demostrar cambios significativos posterior al uso de broncodilatador.

\subsection{Pletismografía}

Existe obstrucción fija severa al flujo aéreo, distensibilidad disminuida, resistencia aumentada y escasa respuesta a salbutamol. Se encuentra un aumento de la capacidad pulmonar total (CPT) y del cociente VR/CPT $>30 \%$. La función pulmonar no mejora significativamente durante los primeros 2 años de enfermedad.

\subsection{Saturometría $\left(\mathrm{SpO}_{2}\right)$ nocturna}

No existen protocolos universalmente aceptados para el aporte de $\mathrm{O}_{2}$; sin embargo, se recomienda suplemento de $\mathrm{O}_{2}$ para lograr $\mathrm{SpO}_{2}$ $\geq 93 \%$ y prevenir hipertensión pulmonar y poliglobulia. Los requerimientos adicionales de $\mathrm{O}_{2}$ deben ser considerados empleando $\mathrm{SpO}_{2}$ continua nocturna en pacientes con: $\mathrm{SpO}_{2}$ promedio $<95 \%$; y/o más de $10 \%$ del tiempo saturando $<93 \%$; o desaturaciones $<85 \%$, mayores a 10 segundos de duración (aunque sea un sólo episodio); desaturaciones $<85 \%$, menores de 10 segundos de duración en mayores de 2 años. En los pacientes que requieran aporte de $\mathrm{O}_{2}$ adicional por más de 3 semanas deberían controlarse con $\mathrm{SpO}_{2}$ nocturna según el criterio médico (mensual, bimensual, trimestral) durante el primer año post injuria. Cada disminución de $\mathrm{O}_{2}$ debe mantenerse por al menos 3 semanas antes de continuar. Cada disminución de $\mathrm{O}_{2}$ debe registrarse junto a la $\mathrm{SpO}_{2}$ aislada diurna y ser corroborada siempre con la $\mathrm{SpO}_{2}$ nocturna. La determinación de los requerimientos de $\mathrm{O}_{2}$ antes del alta exige una monitorización prolongada con mediciones de $\mathrm{SpO}_{2}$ en diversas condiciones como sueño, alimentación y actividad; igual método se recomienda para decidir la suspensión, la cual debe hacerse de forma cautelosa. Los pacientes con hipoxemia mayor a un año deberían ser controlados con $\mathrm{SpO}_{2}$ nocturna cada 36 meses. 


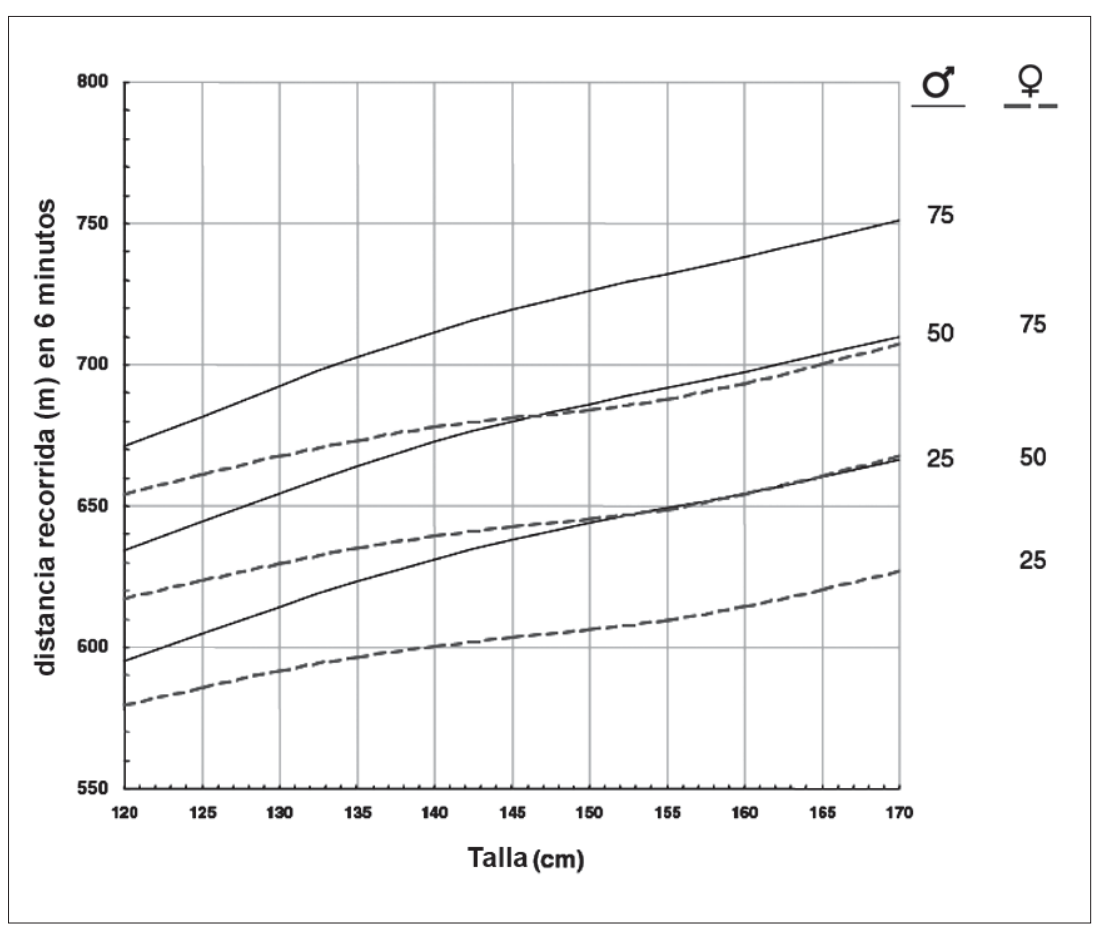

Figura 1. Nomograma de distancia caminada en el TM6 según sexo y talla, según Li et $\mathrm{a}^{98}$.

\subsection{Test de marcha de 6 minutos (TM6)}

En niños con BO post-infecciosa ha demostrado ser un test reproducible y bien tolerado. Se recomienda para el seguimiento y planificación de pautas de entrenamiento. Este test puede realizarse en pacientes $\mathrm{O}_{2}$ dependientes, siendo recomendada la utilización de su fuente de
$\mathrm{O}_{2}$ habitual, idealmente mochila con $\mathrm{O}_{2}$ líquido. Recomendamos la utilización de los valores de referencia de Li y cols ${ }^{98}$ (Figura 1), para pacientes con estatura mayor de $120 \mathrm{~cm}$. Para estaturas menores puede utilizarse los valores de referencia de Geiger y cols ${ }^{58}$ con una periodicidad mínima de 2 veces al año (Tabla 2).

Tabla 2. Valores de distancia caminada en niños sanos según edad y $\operatorname{sex}^{58}$

\begin{tabular}{lllcclc}
\hline Género & Edad (años) & $\mathbf{n}$ & mediana (rango) & $\mathbf{9 5 \%}$ rango & Media \pm DS & 95\% IC \\
\hline Hombre & 3 a 5 & 22 & $544,3(318,0-680,6)$ & $319,7-680,6$ & $536,5 \pm 95,6$ & $494,1-578,9$ \\
& 6 a 8 & 66 & $584,0(455,0-692,0)$ & $471,0-659,3$ & $577,8 \pm 56,1$ & $564,0-591,6$ \\
& 9 a 11 & 57 & $667,3(540,2-828,0)$ & $556,2-801,5$ & $672,8 \pm 61,6$ & $656,5-689,2$ \\
& 12 a 15 & 80 & $701,1(276,1-861,0)$ & $600,7-805,3$ & $697,8 \pm 74,7$ & $681,2-714,4$ \\
& $\geq 16$ & 55 & $727,6(569,0-865,3)$ & $616,9-838,4$ & $725,8 \pm 61,2$ & $709,3-742,4$ \\
Mujer & 3 a 5 & 25 & $492,4(352,0-713,3)$ & $364,5-692,7$ & $501,9 \pm 90,2$ & $464,7-539,1$ \\
& 6 a 8 & 46 & $578,3(406,0-707,2)$ & $448,8-693,9$ & $573,2 \pm 69,2$ & $552,7-593,8$ \\
& 9 a 11 & 62 & $655,8(548,0-818,0)$ & $572,0-760,5$ & $661,9 \pm 56,7$ & $647,4-676,3$ \\
& 12 a 15 & 71 & $657,6(485,5-785,0)$ & $575,2-746,5$ & $663,0 \pm 50,8$ & $651,0-675,0$ \\
& $\geq 16$ & 44 & $660,9(557,0-774,3)$ & $571,2-756,2$ & $664,3 \pm 49,5$ & $649,3-679,3$ \\
\hline
\end{tabular}




\subsection{Test de provocación con metacolina}

La presencia de hiperreactividad bronquial (HRB) es un hallazgo frecuente en pacientes con $\mathrm{BO}$ post infecciosa y su determinación es inespecífica.

\section{Radiología e imágenes}

\subsection{Radiografía (Rx) simple de tórax}

Constituye una herramienta para el diagnóstico inicial, evaluación de las lesiones y determinación de la extensión. Los hallazgos en la Rx de tórax son heterogéneos, pudiendo ser normal en algunos casos. Las alteraciones pueden ser divididas en dos categorías:

a. Alteración unilateral: Síndrome de SwyerJames-McLeod o colapso pulmonar total. El síndrome de Swyer-James-McLeod es una manifestación radiológica en placa simple de tórax de $\mathrm{BO}$ post-infecciosa, caracterizada por un pulmón pequeño e hiperlúcido unilateral debido al compromiso pulmonar asimétrico, con mayor atrapamiento aéreo del pulmón afectado. La alteración generalmente se hace más evidente en Rx de tórax obtenida en espiración.

b. Alteración bilateral: Manifestada como hiperinsuflación y pulmones hiperlúcidos con disminución de la vasculatura pulmonar o un cuadro mixto de atelectasia, hiperinsuflación y engrosamiento peribronquial (Figura 2).

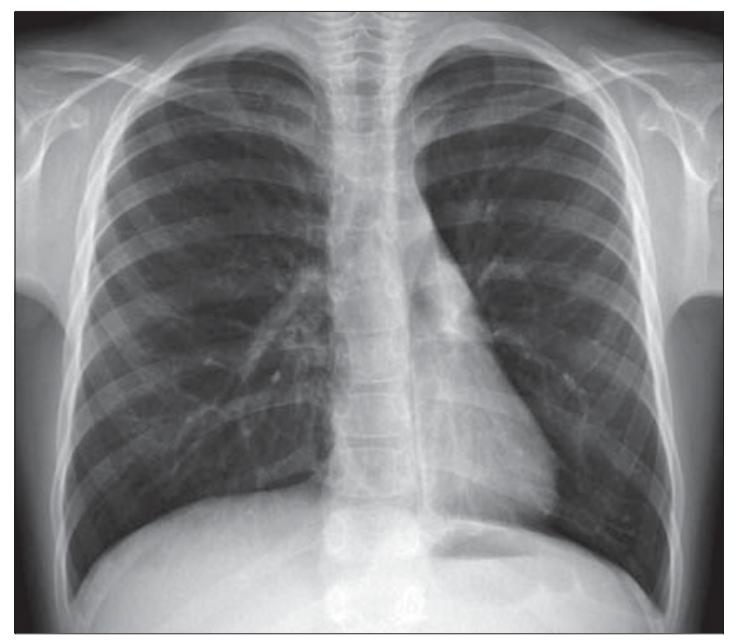

Figura 2. Rx de tórax de paciente de 9 años. Nótese la importante disminución del volumen del pulmón izquierdo que es hiperlúcido y presenta una disminución de vascularización. El hilio pulmonar izquierdo esta descendido por un mayor compromiso cicatrizal del lóbulo inferior.

\subsection{Broncografía}

Esta técnica ha sido abandonada por ser invasiva y se ha reemplazado por la TAC de alta resolución.

\subsection{TAC de alta resolución (HRCT)}

La TAC es reconocida como una importante herramienta para el diagnóstico de $\mathrm{BO}$, capaz de demostrar con mayor precisión anormalidades en la VA pequeña así como las consecuencias de éstas. Existen áreas de hiperinsuflación localizadas, patrón en mosaico con zonas de baja densidad que reflejan atrapamiento aéreo y otras de pulmón normal con apariencia de vidrio esmerilado en espiración, áreas de disminución de flujo vascular, atelectasias cicatrizales y dilatación bronquial segmentaria y subsegmentarias. Esta técnica ha demostrado que el compromiso pulmonar siempre es bilateral y que la manifestación unilateral previamente descritas como síndrome de Swyer-James en Rx simple de tórax era debido a la menor sensibilidad de esta técnica para detectar daños menores.

\section{Manifestaciones en HRCT}

Las alteraciones tomográficas reflejan los cambios morfológicos y funcionales producidos. Un daño extenso se manifestará por atelectasias cicatrizales. La obstrucción parcial de la vía aérea producirá atrapamiento aéreo con aéreas hiperlúcidas de baja densidad. Dado que los cambios son sectoriales se produce un patrón descrito como en mosaico que se manifiesta mejor en espiración (Figura 3). A su vez las alteraciones funcionales producidas en las zonas de atrapamiento aéreo acentúan la hiperlucidez pulmonar. Se clasifican en:

1. Signos directos:

a) Engrosamiento de la pared bronquiolar.

b) Impactación mucosa del lumen bronquiolar.

\section{Signos Indirectos:}

a) Atrapamiento aéreo, definido como áreas de menor atenuación pulmonar, que llamamos difuso cuando compromete un lóbulo o todo un pulmón, o focal cuando compromete sectores de un lóbulo determinando el patrón descrito como atenuación en mosaico.

b) Disminución del volumen pulmonar.

c) Disminución del diámetro de los vasos hiliares o periféricos.

3. Otros hallazgos no relacionados directamente con la afectación bronquiolar incluyen:

a) Engrosamiento de la pared bronquial.

b) Bronquiectasias.

c) Compromiso del espacio aéreo por sobreinfección agregada. 

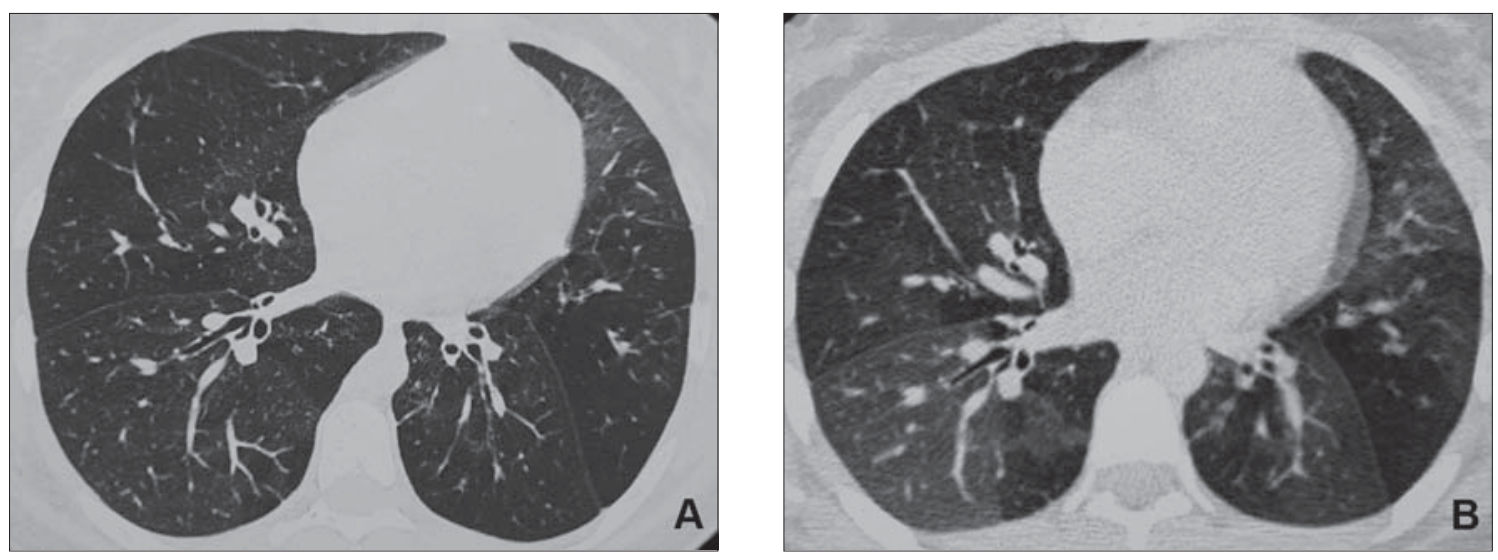

Figura 3. TAC de tórax en paciente de 12 años. A: Inspiración. B: Espiración. Se demuestra el atrapamiento aéreo en las zonas comprometidas por la BO como áreas de menor densidad que se hacen más evidente en espiración. El pulmón normal en espiración pierde aire haciéndose más denso. Nótese además un compromiso bronquial con aumento de calibre y engrosamiento de sus paredes.

En bronquios de tamaño intermedio y grande se describen bronquiectasias especialmente dentro de los lóbulos colapsados. El mayor grado de fibrosis representaría el estado final del compromiso morfológico de la VA y parénquima vecino visualizado en la TAC como atelectasia cicatricial.

\subsection{Cintigrafía pulmonar}

Se aprecian múltiples defectos tanto en perfusión como en ventilación. Es de utilidad para identificar zonas que están excluidas de la perfusión (casos más leves).

\section{Fibrobroncoscopía (FBC)/Lavado broncoalveolar (LBA)}

La FBC puede descartar otras patologías de obstrucción crónica de VA. Está indicada para remover tapones mucosos en atelectasias persistentes. El papel del LBA no ha sido validado en la $\mathrm{BO}$; podría ser de utilidad para determinar la presencia de nuevos microorganismos o colonizaciones crónicas.

\section{Cuidado en el policlínico broncopulmonar}

\section{Evaluación anual}

Todos los pacientes con $\mathrm{BO}$ requieren una evaluación periódica anual clínica/laboratorio completa, determinando los progresos alcanzados durante el último año e introduciendo cambios -eventuales- en el tratamiento de su condición. No se recomienda la Rx de tórax de manera rutinaria (excepto durante una excerbación).
Es ideal una pletismografía anual si se dispone (en aquellos mayores de 6 años), así como una espirometría determinando la posible respuesta a salbutamol (400-800 $\mu \mathrm{g})$. En los pacientes en riesgo (uso frecuente de esteroides sistémicos), debe considerarse una densitometría ósea anual, y si ésta es normal, repetirla cada dos años. Los exámenes de laboratorio de rutina incluyen: hemograma, perfil bioquímico, electrolitos, creatinina, calcio, magnesio, fósforo, glicemia, pruebas de función hepática y de coagulación, colesterol total y fracciones, vitamina $\mathrm{D}$, gases en sangre. Deben revisarse -como rutina- las técnicas kinésicas aprendidas y la forma de aplicación de cada una de ellas. Se debe poner énfasis en el crecimiento y desarrollo puberal, discutiendo aspectos de fertilidad en aquellos pacientes adolescentes.

\section{Evaluación inicial/periódica en el policlínico broncopulmonar}

La evaluación inicial en el policlínico broncopulmonar tiene por propósito determinar los criterios diagnósticos y excluir otras condiciones clínicas que simulen BO. Se debe identificar el agente causal, los factores de riesgo, el grado de función pulmonar, la existencia de respuesta o no salbutamol, la presencia de bronquiectasias $\mathrm{y}$ un resumen de toda la medicación actualmente empleada. Asimismo se requiere una evaluación psicológica y social por un especialista. Se sugiere un control cada 2-3 meses en forma ambulatoria para determinar la adherencia al tratamiento, posibles recaídas o exacerbaciones, variaciones en la función pulmonar y crecimiento, así como nuevos agentes en los cultivos. 


\subsection{Investigaciones de rutina en el paciente recién diagnosticado}

Un paciente que cumpla con los criterios diagnósticos de $\mathrm{BO}$ post infecciosa antes descritos requiere al menos:

a. $\mathrm{Rx}$ de tórax reciente (AP, lateral).

b. Espirometría con curva flujo volumen (en los mayores de 6 años) con evaluación de respuesta a salbutamol $400 \mu \mathrm{g}$.

c. Oscilometría de impulso (en los menores de 6 años).

d. Pletismografía de ser posible (en los mayores de 6 años).

e. Hemograma completo, perfil bioquímico, creatininemia, electrolitos, calcio, magnesio, fósforo, glicemia en ayunas, pruebas de función hepática y de coagulación, colesterol total y fracciones, vitaminas A y D, Ig E específica para Aspergillus, orina completa, gases en sangre.

f. Cultivo cuantitativo de secreción traqueal.

g. Audiometría con impedanciometría (sujetos de riesgo por uso de antibióticos).

h. Determinación de peso, talla e índice de masa corporal (IMC).

i. $\mathrm{SpO}_{2}$ en reposo, $\mathrm{SpO}_{2}$ nocturna.

j. Test de marcha de 6 minutos.

k. Evaluación de fuerza muscular respiratoria (al menos presión inspiratoria máxima PIM).

\subsection{Evaluación y soporte psicológico}

Todo paciente con BO post infecciosa requiere de una evaluación inicial por un psicólogo, centrada en el proceso de aceptación de la enfermedad y funcionamiento familiar.

\subsection{Evaluación asistente social}

Todo paciente con $\mathrm{BO}$ post infecciosa requiere de una evaluación inicial del servicio social de cada centro, evaluando las redes de apoyo familiares y comunitarias.

\subsection{Evaluación a domicilio (enfermera, kinesiólogo)}

Idealmente todo paciente con $\mathrm{BO}$ requiere una evaluación a domicilio con el propósito de evaluar factores de riesgo, contaminantes intradomiciliarios, necesidades educativas.

\section{Transición al policlínico broncopulmonar de adultos}

La transición debe ocurrir en el contexto del desarrollo biológico del niño. Las EPC retrasan el comienzo de la pubertad y produce un menor grado de interacción y capacidad de socialización laboral y sentimental. La adolescencia es un período crítico en que ocurren numerosos cambios físicos y psíquicos por ello la transición debe ser flexible e individualizada alrededor de los 16 años. Los pacientes deben conocer su propia historia de salud. Se requiere una adecuada transferencia de información, lo cual implica más que un simple resumen con una larga lista de medicaciones o de exámenes. El centro receptor debe conocer el estado funcional, la progresión de la enfermedad, condiciones asociadas, complicaciones, tratamientos previos, historia nutricional, cultivos microbiológicos y sus sensibilidades, estado puberal y de fertilidad, aspectos psicosociales, expectativas de vida y la adherencia familiar. Se debe conocer qué espera realmente el adolescente encontrar, ya que es evidente que el estilo de cuidado en los sistemas de adultos es diferente al estilo pediátrico.

\section{Admisión al hospital}

\section{Hospitalización}

Razones para ingreso al hospital:

a. Uso antibiótico EV por exacerbación aguda.

b. Broncoscopía flexible/pH-metría (según cada centro).

c. Incremento en los requerimientos de $\mathrm{O}_{2} \mathrm{O}$ parámetros ventilatorios.

d. Estudio polisomnográfico o $\mathrm{SpO}_{2}$ continuo.

e. Ingreso a pabellón electivo para colocación de catéter de larga duración/gastrostomía/sonda nasoyeyunal.

f. Educación del paciente/familiares.

g. Razones sociales o abandono.

El examen físico deberá poner énfasis en:

a. Sistema respiratorio: tos, sibilancias, presencia de esputo (calidad, cantidad, color, consistencia), hemoptisis, dolor torácico, disnea en reposo, tolerancia a la marcha/ejercicio. Deberá registrarse la $\mathrm{SpO}_{2}$ en reposo $\left(\sin \mathrm{O}_{2}\right)$ y dormido.

b. Gastrointestinal: apetito, pirosis, náuseas, vómitos, dolor abdominal, pérdida de peso, uso de gastrostomía.

c. Genitourinario: nicturia, poliaquiuria, disuria.

d. Oídos/nariz/garganta: obstrucción nasal, epistaxis, rinitis, pérdida de olfato.

e. Neuromuscular: cefalea, parestesias, debilidad muscular, dolor torácico.

Se debe tomar una historia social detallada, con especial cuidado en ausentismo escolar, asistencia a sala cuna/jardines, mascotas y exposición a tabaco. Debe registrarse en forma com- 
pleta el tratamiento utilizado, requerimientos y dosis de corticoides, técnica inhalatoria, presencia de alergia a medicamentos. Registrar la presión arterial, con especial atención en aquellos que usan esteroides sistémicos. Debe preguntarse o averiguar el último cultivo de esputo y su sensibilidad antibiótica.

\section{Laboratorio e investigaciones}

Los exámenes de laboratorio de ingreso deben ser los mismos que deben repetirse cada 612 meses dependiendo de la gravedad de cada paciente. La Rx de tórax deberá evaluarse caso a caso. Deben revisarse las técnicas kinésicas aprendidas y la forma de aplicación de cada una de ellas. Cada evaluación en el policlínico/hospitalización deberá estar acompañada de una espirometría (en todos aquellos pacientes con capacidad de hacerla, independiente del valor previo o más bajo). Debe de registrase la espirometría más reciente $\left(\mathrm{FEF}_{25-75}, \mathrm{CVF}\right.$ y $\left.\mathrm{VEF}_{1}\right)$ así como el mejor valor personal histórico.

\section{Soporte ventilatorio (criterios)/Unidad de pacientes críticos pediátricos (UPC)}

Se recomienda el ingreso a UPC:

- Requerimiento de $\mathrm{FiO}_{2}$ en forma aguda $\geq 0,40$ 0,50 (según cada centro).

- Necesidad de apoyo ventilatorio mecánico no invasivo.

- Requerimiento de administración de medicamentos nebulizados frecuentes (intervalos menores que cada 2 horas) o continuos.

- Necesidad de kinesioterapia respiratoria frecuente (higiene bronquial).

- Presencia de insuficiencia respiratoria parcial o global, primaria o secundaria, que requiera de apoyo ventilatorio mecánico invasivo, convencional o no convencional y/o, requerimiento de apoyo con drogas vasoactivas y/o, requerimiento de monitorización invasiva.

- Pacientes que al momento de la admisión no se encuentran en situación crítica, pero que requieren de los servicios de monitorización de una UPC y aquellos que se encuentran en riesgo de necesitar en el corto plazo tratamiento intensivo.

\subsection{Soporte ventilatorio}

3.1.1. Ventilación mecánica no invasiva (VMNI): En niños no existe evidencia, sin embargo, su uso se ha popularizado y extendido a diferentes escenarios clínicos, entre los que se cuentan la insuficiencia respiratoria aguda hipoxémica pura e hipercápnica, pacientes inmuno- suprimidos con falla respiratoria, shock séptico, entre otros. Podría ser recomendada en:

a) Dificultad respiratoria moderada-severa establecida por el aumento del trabajo respiratorio (uso de musculatura accesoria) y frecuencia respiratoria mayor al límite superior para la edad, que no mejora con la terapia inicial.

b) Necesidad de $\mathrm{FiO}_{2} \geq 0,5$ y $\mathrm{SpO}_{2}<93 \%$ o relación entre la $\mathrm{PaO}_{2}$ y la $\mathrm{FiO}_{2}: \mathrm{PaO}_{2} / \mathrm{FiO}_{2}$ $<150 \mathrm{mmHg}$.

c) Hipercapnia con $\mathrm{PaCO}_{2}>45 \mathrm{mmHg}\left(\mathrm{si} \mathrm{PaCO}_{2}\right.$ basal es normal o $15 \mathrm{mmHg}$ sobre su basal), pero $\mathrm{pH}$ no inferior de 7,25.

d) Progresión del compromiso pulmonar clínico y radiológico.

\subsubsection{Ventilación mecánica Invasiva (VMI):}

La VMI debiera evitarse en pacientes con BO en consideración al daño pulmonar de base (mayor riesgo de daño pulmonar inducido por ventilación mecánica o VILI) y al patrón ventilatorio obstructivo moderado-severo, con el consiguiente riesgo de mayor atrapamiento aéreo y barotrauma durante la exacerbación. Las indicaciones de VMI en exacerbación de BO son:

a) Paro cardiorrespiratorio.

b) Compromiso de conciencia progresivo.

c) Hipoxemia refractaria pese a tratamiento adecuado.

d) Acidosis respiratoria refractaria a tratamiento.

Si la VMI es aplicada, considerar volúmenes corrientes bajos (evitar volutrauma y barotrauma) y PEEP que eviten el atelectrauma con el consiguiente biotrauma. En el caso de la enfermedad obstructiva, los tiempos espiratorios debieran ser más prolongados de lo habitual en consideración a las constantes de tiempo espiratorias mayores. Si el paciente mantiene respiración espontánea entre los ciclos mandatarios, debiera intentarse disminuir la hiperinsuflación dinámica manteniendo un PEEP cercano al auto PEEP (aproximadamente $75-80 \%$ del PEEP intrínseco), con una presión de soporte suficiente para sostener las respiraciones espontáneas del niño. La meta es tolerar $\mathrm{PaCO}_{2}$ elevadas que no signifiquen un $\mathrm{pH}<7,20$ (hipercapnia permisiva) y $\mathrm{PaO}_{2}$ no menores a $55 \mathrm{mmHg}$ con $\mathrm{SpO}_{2} \geq 88 \%$ (hipoxemia permisiva).

\section{Catéter venoso de larga duración}

Se debe considerar el uso de catéteres venosos centrales de larga duración como una alternativa en aquellos casos con frecuentes exacerbaciones respiratorias que requieran tratamiento antibióti- 
co prolongado. Requieren ser insertados y retirados quirúrgicamente, y el criterio de retirada estará dado por el fin de la necesidad por la que fue instaurado o por problemas graves a los que no se pueda dar solución. Las indicaciones para su implantación son:

1. Necesidad de tratamiento antibiótico endovenoso prolongado, con dificultad de acceso intravenoso periférico disponible.

2. Administración repetida y a largo plazo de tratamiento antibiótico (más de tres períodos en el año).

3. Acceso a largo plazo, continuo o intermitente, para toma de muestras sanguíneas.

\subsection{Tipos de catéteres venosos centrales de larga duración}

La elección del tipo de catéter dependerá de la edad del niño, características anatómicas, condición clínica, disponibilidad de insumos y experiencia local en el uso de catéteres.

4.1.1. Catéter tunelizado: Se trata de catéteres centrales externos insertados mediante técnica tunelizada percutánea. Pueden tener una, dos o tres luces. En este grupo se incluyen los catéteres Hickman, Broviac y Groshong.

4.1.2. Catéter implantados o de reservorio subcutáneo: Constan de un portal o cámara con una membrana de silicona autosellante unido a un catéter tunelizado bajo la piel. A este reservorio se accede por punción a través de piel intacta que permite múltiples punciones. PortA-Cath, Infuse-A-Port, Vital-Port, LifePort, Chemo-Port, Mediport o Norport son las marcas conocidas. Se puncionan con agujas especiales llamadas tipo Gripper o Huber.

\subsection{Cuidados generales de los catéteres de larga duración}

a) Los centros hospitalarios deben contar con protocolos de elección, implantación, uso, cuidados, mantención y acciones frente a complicaciones.

b) Los centros de atención ambulatoria deben tener conocimiento de estos catéteres y controlar continuamente el cuidado ambulatorio y reforzar educación al paciente y familia respecto a estos.

c) Seguir recomendaciones del Center for Disease Control and Prevention o protocolos de comité de infecciones intrahospitalarios locales para la prevención de infecciones del catéter.

d) Realizar heparinización continua (recomendación según tipo de catéter), para asegurar utilidad del dispositivo. e) Educar a cuidadores formales, informales y pacientes respecto a los cuidados de los catéteres de larga duración, considerando los cuidados hospitalarios y ambulatorios.

\section{Criterios de alta}

Considerar el alta si cumple todos los siguientes criterios:

a) Buena tolerancia oral, recibiendo antibióticos por VO por al menos $24 \mathrm{~h}$ sin vómitos.

b) Afebril al menos $24 \mathrm{~h}$.

c) $\mathrm{Sin}$ requerimiento de $\mathrm{O}_{2}\left(\mathrm{SpO}_{2} \geq 93 \%\right.$ por al menos $8 \mathrm{~h}$ o dormido una noche) o en sus parámetros ventilatorios $/ \mathrm{O}_{2}$ habituales.

d) Técnicas kinésicas evaluadas y/o supervisadas adecuadas.

e) En adolescentes/adultos o pacientes con exacerbación asociada a $P$. aeruginosa el alta ocurre luego de 14 días de terapia antibiótica bi-asociada.

\section{Cuidado respiratorio}

\section{Manejo de la exacerbación}

Los pacientes que desarrollan $\mathrm{BO}$ post infecciosa presentan durante su evolución, principalmente los primeros años posteriores a la injuria inicial. Hasta el $80 \%$ de estos pacientes requieren hospitalizaciones reiteradas por aumento de los síntomas respiratorios, siendo su principal gatillante las infecciones respiratorias agudas. Las exacerbaciones respiratorias pueden manifestarse con cambios sutiles en sintomatología respiratoria, estado general, calidad o cantidad de secreciones bronquiales. Ya que la mayoría de los pacientes con $\mathrm{BO}$ presentan bronquiectasias, se podría definir una exacerbación como la presencia de 4 ó más de los siguientes: cambios en el esputo; aumento de la disnea; aumento de la tos; fiebre mayor a $38{ }^{\circ} \mathrm{C}$; aumento de sibilancias; malestar o fatiga; disminución en la función pulmonar; cambios en la $\mathrm{Rx}$ de tórax $\mathrm{y} / \mathrm{o}$ en la auscultación pulmonar.

\section{Antibióticos}

Dependerá de la identificación de los microorganismos en el cultivo de secreción traqueal, LBA o los microorganismos más habituales de la vía aérea (VA): $S$. aureus, $S$. pneumoniae, $H$. influenzae, Moraxella catharralis. Es necesario administrar durante las exacerbaciones respiratorias prolongando la terapia por al menos 14 días. Frente a toda exacerbación aguda en pacientes con BO post-infecciosa se recomienda el empleo de antibióticos y así disminuir el riesgo de sobreinfección. 


\subsection{Antibióticos endovenosos}

Se sugiere el empleo de antibióticos endovenosos frente a cada hospitalización. La vía oral se reserva para exacerbaciones leves que no requieran hospitalización o frente a un alta inmediata luego de completar 14 días.

\section{Kinesioterapia durante la exacerbación}

No existe evidencia para establecer una recomendación en la exacerbación. Probablemente, las sesiones de kinesiterapia respiratoria debieran ser permanentes, ya que la eliminación efectiva de secreciones retenidas, disminuye la carga bacteriana presente en estos pacientes colonizados en forma crónica y permitiría disminuir las exacerbaciones. También, esta estrategia de apoyo permanente a diferentes frecuencias o según necesidad, puede servir de monitoreo del estado particular de las secreciones y el estado general del paciente.

\section{Ventilación: estrategias sugeridas en una exacerbación}

Existe poca evidencia para recomendar su empleo en exacerbaciones; sin embargo, ha sido empleado en algunos pacientes con BO subsidiarios del Programa AVNI. Teóricamente, el uso de BiPAP, podría disminuir el riesgo de complicaciones de la ventilación convencional. Una buena alternativa para entregar $\mathrm{O}_{2}$ es mediante una conexión en $\mathrm{T}$ colocada a la salida del BiPAP. Con flujos de $\mathrm{O}_{2}$ inferiores a $3 \mathrm{~L} / \mathrm{min}$ generalmente sólo es necesario usar un humedificador tipo burbuja, en caso de flujos mayores podría ser necesario sistemas de termohumedificación tradicionales tipo sobrepaso o aquellos compatibles con los generadores de flujo. El escape de flujo a través de la interfase es causa frecuente de desaturación, que se mejora reposicionando y adaptando la mascarilla a la cara del paciente.

\section{Nebulizaciones con solución salina hipertónica}

Durante estas exacerbaciones el uso de nebulizaciones con suero hipertónico podría tener un papel terapéutico al mejorar el clearance mucociliar y utilidad en toma de muestra de expectoración tanto para cultivo como para estudio inflamatorio. Las dosis utilizadas de solución salina es $3 \%$ en $<4$ años (incluido lactantes) y $7 \%$ en niños $>4$ años, con un perfil de seguridad adecuada. Se nebuliza $5 \mathrm{ml}$ de solución por 12 minutos con un nebulizador ultrasónico (Pari jet plus) para lograr una mejor acción y efecto. Se sugiere premedicación con salbutamol
(400 $\mu \mathrm{g} 15$ minutos antes) para evitar el desarrollo de broncoespasmo. No existen publicaciones que evalúen su uso y efectividad en $\mathrm{BO}$ post-infecciosa.

\section{Broncodilatadores}

Los broncodilatadores son ampliamente usados en las exacerbaciones respiratorias de pacientes con $\mathrm{BO}$ a pesar de que la función pulmonar muestra obstrucción fija de la VA con pobre respuesta a éstos. En forma empírica, se sugiere administrar broncodilatadores vía aerosol presurizado (dosis mayores de $400 \mu \mathrm{g} / \mathrm{vez}$ ) utilizando espaciador apropiado para la edad en pacientes con exacerbación y durante el tiempo que duren los síntomas especialmente en aquellos que manifiesten alivio de sus síntomas. En general no se observa una respuesta significativa.

\section{Esteroides sistémicos e inhalados}

Aunque los esteroides sistémicos son frecuentemente usados, su efectividad en mejorar el pronóstico de pacientes con $\mathrm{BO}$ es desconocida. Algunos sugieren la administración precoz de esteroides (fase aguda) en un intento de modificar la respuesta fibroblástica. El uso de pulsos de metilprednisolona puede ser usado como alternativa en la enfermedad severa $(30 \mathrm{mg} / \mathrm{kg}$, máximo $1 \mathrm{~g}$, por tres días consecutivos). Esta forma de administración permite reducir los efectos adversos del uso prolongado de esteroides. No existen ensayos clínicos que demuestren un claro beneficio del uso de esteroides durante la enfermedad, por ello su empleo debe ser evaluado caso a caso teniendo en cuenta los efectos adversos. En relación al uso de esteroides inhalados, se considera que existe dificultad en el depósito de los mismos en una VA periférica con obstrucción fija; sin embargo, algunos autores prefieren el uso de esteroides inhalados en dosis altas (Budesonida $>1.000 \mu \mathrm{g}$ ) con la intención de disminuir los efectos adversos de los sistémicos. No existen estudios controlados que evalúen la eficacia de los esteroides inhalados en el manejo de la BO post-infecciosa por lo cual su uso es controvertido y no se recomienda.

\section{Azitromicina}

No existen estudios que evalúen el uso de macrólidos en niños con BO post-infecciosa. El uso de azitromicina oral, en dosis de $10 \mathrm{mg} / \mathrm{kg}$ tres veces por semana, se basa en la eficacia demostrada en otras patologías obstructivas crónicas. 


\section{Inmunoglobulinas EV}

Su efectividad no ha sido probada. Se sugiere que dosis inmunomoduladoras de inmunoglobulina EV (1-2 g/kg/día) administrada mensualmente podría ser útil en pacientes con enfermedad severa.

\section{Anticuerpos monoclonales para TNF alfa}

El uso de anti-TNF alfa no se recomienda por estar asociada con eventos adversos serios.

\section{Complicaciones: Bronquiectasias/Hemoptisis/neumotórax}

\subsection{Bronquiectasias}

La Rx de tórax se encuentra frecuentemente alterada aunque generalmente los hallazgos son inespecíficos: atelectasias, opacidades reticulares y aglutinación broncovascular. Puede haber hallazgos específicos: bronquios dilatados con pared engrosada e imagen en anillo. El diagnóstico de bronquiectasias requiere siempre de un TAC pulmonar.

\subsection{Hemoptisis}

Es una complicación asociada a las bronquiectasias. En la mayoría de casos son leves y autolimitadas. Se considera hemoptisis de riesgo vital aquella mayor a $8 \mathrm{ml} / \mathrm{kg}$. La angio TAC permite detectar el vaso sanguíneo que está sangrando.

\subsection{Neumotórax}

La presencia de dolor torácico y disnea sugiere su presencia. Puede ser asintomático. La $\mathrm{Rx}$ tórax en general confirma el diagnóstico, aunque puede no detectar un neumotórax leve. La ecografía de tórax mejora la sensibilidad diagnóstica.

\section{Cirugía de tórax}

La resección pulmonar es un recurso de difícil administración. No debe ser considerada como una "pérdida" pulmonar un segmento que produce broncorrea crónica y recibe de manera frecuente cursos de antibióticos. Se debiera considerar candidato a cirugía a aquel paciente con EPC preferentemente localizada grave (lóbulo o segmento), con el resto o la mayoría del pulmón sano o desproporcionadamente menos comprometido asociado a una mala calidad de vida, definida como:

a) Ausencia escolar frecuente por exacerbaciones.

b) Hospitalizaciones frecuentes (3-4 al año).

c) Incapacidad de realizar actividad física debido a la broncorrea y tos. d) Requerimiento frecuente de cursos antibióticos (riesgo de resistencia).

e) Broncorrea permanente e invalidante socialmente (sonido/olor).

\section{Cuidado no respiratorio}

\section{Evaluación y apoyo nutricional}

\subsection{Generalidades}

Existe una prevalencia significativa de desnutrición en niños con EPC; junto al tipo de patología, edad de inicio, duración y severidad influyen el grado de compromiso nutricional. En estos pacientes con frecuencia coexisten diferentes factores que favorecen la desnutrición. La prevención, el diagnóstico precoz de desnutrición y el apoyo oportuno cobran especial interés, no solamente para evitar el compromiso del crecimiento, sino que también secuelas a mediano y largo plazo en el desarrollo neurológico. La desnutrición influye en el crecimiento y desarrollo del pulmón, especialmente durante los primeros dos años de la vida, y se relaciona con la función de la musculatura respiratoria. Por otro lado, las infecciones aumentan los requerimientos y favorecen un círculo vicioso en que aumenta la morbimortalidad y la desnutrición que a su vez disminuye los mecanismos defensivos pulmonares, aumentando el riesgo de infecciones.

$\mathrm{Se}$ ha descrito en los pacientes con $\mathrm{BO}$ una prevalencia de desnutrición aguda de entre $3 \mathrm{y}$ $20 \%$ y de desnutrición crónica de $10 \%$, esta última más acentuada en los niños mayores de 10 años. Inicialmente existe deterioro exclusivo del peso, asociado a cuadros infecciosos agudos graves o recurrentes y posteriormente se compromete el crecimiento estatural, produciéndose una normalización de la relación entre el peso y la estatura. Mediante una detección oportuna y un apropiado apoyo nutricional es posible lograr una recuperación en la primera fase, al igual que lograr un ritmo normal de crecimiento en talla. No siempre se logra la recuperación de un mejor canal de crecimiento (catch-up growth), persistiendo retraso estatural, lo cual sumado a la menor actividad física y mantención de altos aportes calóricos, puede favorecer posteriormente el desarrollo de sobrepeso, presente en alrededor de $10 \%$ de los niños con $\mathrm{BO}$ en edad escolar.

\subsection{Objetivo nutricional}

El objetivo principal del apoyo nutricional en los pacientes con EPC es la optimización del crecimiento y desarrollo, para favorecer una me- 
jor evolución de la patología de base, de la calidad de vida y para prevenir el desarrollo de secuelas y patologías crónicas.

\subsection{Evaluación y monitorización nutricional}

Es necesario monitorizar en forma regular la ingesta, a través de una anamnesis nutricional detallada que considere hábitos, horarios, conducta, encuesta y registros de ingesta. También hay que medir evolutivamente peso, talla y perímetro craneano, construyendo curvas que permitan visualizar la velocidad del crecimiento del paciente, el patrón de referencia actualmente recomendado es el de la OMS (http://www.minsal. cl), valorando los índices antropométricos de peso para edad $(\mathrm{P} / \mathrm{E})$, talla para la edad $(\mathrm{T} / \mathrm{E})$ y peso para la talla $(\mathrm{P} / \mathrm{T})$. También es posible estimar en el examen físico la masa magra y la masa grasa a través de pliegues cutáneos y buscar carencias específicas, como es por ejemplo el déficit de hierro, frecuente en niños con EPC. Los exámenes de laboratorio constituyen medidas de apoyo en algunas ocasiones, pero en general tienen baja sensibilidad para diagnosticar déficit nutricional. La albúmina plasmática es un marcador tardío de depleción proteica y aunque la pre-albúmina tiene menor vida media, es poco específica. Los niveles plasmáticos de vitaminas son útiles en casos escogidos, en cuanto a minerales, se requiere del hemograma para pesquisar anemia y de la ferritina plasmática para evaluar depósitos de hierro. El status de zinc es más complejo de medir en la práctica clínica, se estudia si existe ingesta marginal y cuadro clínico compatible, por último, calcio, fósforo y fosfatasas alcalinas permiten aproximarse a la situación del metabolismo óseo. Es posible estimar los requerimientos de energía a través de fórmulas, pero se puede medir el gasto energético en reposo (GER) a través de la calorimetría indirecta, si está disponible constituye un ele-

Tabla 3. Fórmulas para el cálculo del Gasto energético en reposo (GER)*, OMS 1985

\begin{tabular}{cll}
\hline $\begin{array}{c}\text { Edad } \\
\text { (años) }\end{array}$ & Hombre & Mujer \\
\hline $0-3$ & $(60,9 \times$ Peso en $\mathrm{kg})$ & $(61 \times$ Peso en $\mathrm{kg})$ \\
& -54 & -51 \\
3 - 10 & $(22,7 \times$ Peso en $\mathrm{kg})$ & $(22,5 \times$ Peso en $\mathrm{kg})$ \\
& +495 & +499 \\
10 a 18 & $(17,5 \times$ Peso en $\mathrm{kg})$ & $(12,2 \times$ Peso en $\mathrm{kg})$ \\
& +651 & +746 \\
\hline
\end{tabular}

GER en kcal/día. mento objetivo e individualizado para adecuar el aporte calórico (Tabla 3). El estudio de la composición corporal y masa mineral ósea es útil en pacientes en ventilación crónica o con enfermedades neurológicas, la absorciometría con rayos $\mathrm{X}$ de doble energía (DEXA) constituye un método de referencia en clínica, o en su defecto la impedanciometría bioeléctrica (BIA) tetrapolar, que tiene menor costo económico pero presenta mayor variabilidad.

\subsection{Manejo nutricional}

Es recomendable que los aportes energéticos sean individualizados, ya que el mejor indicador de su adecuación es un buen progreso pondoestatural. Éste se define a través de índices antropométricos en rango normal: En los menores de 1 año, peso para la edad (P/E) y en los mayores de 1 año peso para la talla $(\mathrm{P} / \mathrm{T})$ entre $-1 \mathrm{y}+1 \mathrm{DE}$, al igual que talla para la edad (T/E) entre $-2 \mathrm{y}+2$ DE. En los niños mayores, si existe talla baja $(\mathrm{T} / \mathrm{E}<-2 \mathrm{DE})$, debe plantearse lograr un peso armónico a ésta. Los requerimientos calóricos varían de acuerdo a la edad, el sexo y la actividad física y se corrigen de acuerdo al mayor gasto por la patología y el déficit nutricional (Tabla 4). El aporte proteico oscila entre los 2,2 y $2 \mathrm{~g} / \mathrm{kg} / \mathrm{día}$ en el primer año y disminuye gradualmente hasta $1 \mathrm{~g} / \mathrm{kg} /$ día en el adolescente, los requerimientos proteicos son mayores en prematuros y desnutridos.

El primer paso es la optimización de la alimentación habitual que el niño recibe, mediante un mayor fraccionamiento (4 comidas diarias más una o dos colaciones extra), luego se utilizan fortificantes calóricos naturales y posteriormente módulos calóricos. El uso de fórmulas

Tabla 4. Requerimientos de energía*

\begin{tabular}{ccc}
\hline $\begin{array}{l}\text { Edad } \\
\text { (años) }\end{array}$ & $\begin{array}{c}\text { Hombres } \\
\text { (kcal/kg/día) }\end{array}$ & $\begin{array}{c}\text { Mujeres } \\
\text { (kcal/kg/día) }\end{array}$ \\
\hline $0-0,5$ & $113-81$ & $107-82$ \\
$0,6-1$ & $79-80$ & $78-79$ \\
$1,1-3$ & $82,4-83,6$ & $80,1-80,6$ \\
$3,1-6$ & $79,7-74,5$ & $76,5-71,5$ \\
$6,1-9$ & $72,5-68,5$ & $69,3-63,8$ \\
$9,1-12$ & $66,6-62,4$ & $60,8-54,8$ \\
$12,1-15$ & $60,2-55,6$ & $52,0-47,0$ \\
$15,1-18$ & $53,4-50,3$ & $45,3-44,1$ \\
\hline
\end{tabular}

* Las recomendaciones consideran gasto energético total (GET) más energía requerida para crecimiento y nivel de actividad física promedio de cada período etáreo, FAOOMS 2001 (Ref. 77). 
poliméricas es inhabitual en estos pacientes, se recomienda que no reemplacen las comidas de la alimentación regular, sino que se utilicen en forma complementaria. Los pacientes con lactancia materna exclusiva deben suplementarse con vitamina D durante los primeros 6 meses, hierro hasta el año y zinc hasta lograr ingesta adecuada de alimentación sólida. Si existe restricción hídrica o mal progreso ponderal, se puede incrementar la concentración de la fórmula y fortificarla en forma balanceada, para aumentar el aporte calórico sin reducción proporcional del proteico. Se dispone también fórmulas poliméricas de alta densidad calórica, que cubren además los requerimientos de vitaminas y minerales cuando se utilizan como fuente única de alimentación. Si no se logra un aporte adecuado vía oral o si pese a lograrse, no se obtiene un adecuado progreso ponderal, es recomendable el uso de la vía enteral a través de sonda nasogástrica si su uso es a corto plazo. A mediano o largo plazo es preferible el uso de gastrostomía de alimentación, sea como medida temporal o definitiva de acuerdo al motivo de su indicación y la evolución del paciente. Si bien el fraccionamiento es una medida útil, los períodos interprandiales deben permitir un vaciamiento gástrico completo y favorecer un mayor apetito para la siguiente alimentación. Cuando se utiliza la vía enteral, es más fisiológica la alimentación en bolos. Sin embargo, para optimizar la absorción o la tolerancia, se requiere a veces de alimentación enteral continua, preservando períodos cortos de descanso intestinal. En niños no existe evidencia del uso de fórmulas con alto contenido en grasas y bajo en carbohidratos. Éstas no son apropiadas para niños, por su composición desbalanceada y alta carga proteica, osmótica y de solutos, por lo que no se recomiendan.

\section{Gastrostomía/sondas de alimentación}

Si no se logra un aporte adecuado vía oral o si pese a lograrse no se obtiene un adecuado progreso ponderal, es recomendable el uso de la vía enteral a través de sonda nasogástrica si su uso es a corto plazo. A mediano o largo plazo es preferible el uso de gastrostomía de alimentación, sea como medida temporal o definitiva de acuerdo al motivo de su indicación y la evolución del paciente.

\section{Evaluación y apoyo psico-social}

\subsection{Aspectos psicosociales}

La presencia de una EPC lleva a la familia al límite de su capacidad de sobrevivencia; desde esta perspectiva, es necesario comprender y describir los procesos a través de los cuales las familias van exponiendo sus habilidades para enfrentar situaciones relacionadas a la enfermedad, así como la caracterización familiar multiproblemática.

\subsection{Pautas de interacción}

Generalmente, las pautas de interacción de familias en donde existe un integrante con EPC, se ven afectadas por la presencia de estrés vinculados a la misma, desencadenando la polarización de formas de interacción, como rigidez o ausencia total/parcial de pautas de interacción, provocando caos al interior del sistema familiar. Por ello es importante facilitar el florecimiento de un nuevo estilo flexible en las dinámicas vinculadas a la toma de decisiones, límites y roles de cada miembro. Se debe identificar alianzas, entendidas estas como relaciones positivas y que nutren una relación. No debemos olvidar que la estructura familiar puede presentar coaliciones -muchas veces entre enfermo y cuidador- dejando en desmedro la participación de terceros, evidenciándose así, el desligamiento de otros integrantes con la enfermedad. Es importante considerar que la coalición enfermo-cuidador puede traer como consecuencia el fenómeno de parentalización de otro miembro de la familia que no necesariamente es parte de la alianza conyugal.

\subsection{Alteraciones "procesales"}

Durante los períodos de exacerbación de la EPC las familias experimentan procesos complejos identificándose cambios en la capacidad de autorregulación, lo que genera caos o pérdida del equilibrio al interior de ellas. Podemos identificar fenómenos de aglutinación con límites interpersonales difusos, limitada autonomía individual, y un alto grado de reactividad emocional; por otro lado, podemos observar el desligamiento caracterizado por mayor distanciamiento emocional, límites internos más rígidos, los externos más permeables. No es raro observar triangulaciones utilizándose al tercer elemento para encubrir o desactivar un conflicto; muchas veces este tercer elemento corresponde a la misma presencia de la enfermedad.

\subsection{Alteraciones emocionales}

1. Las familias que poseen uno de sus integrantes con necesidades especiales debido a una EPC, son vulnerables a desarrollar alteraciones emocionales en alguno de sus integrantes. La estabilidad emocional de la familia dependerá de cómo este grupo afronte sus propias crisis, en- 
tendiéndose como períodos de agudización. Por ello todo plan de abordaje debe considerar:

1. Fortalecimiento psicológico y social para el grupo familiar.

2. Facilitar la identificación de eventos estresantes adversos vinculados a la enfermedad y/o agudizaciones.

3. Enriquecimiento de las habilidades psicológicas, sociales e instrumentales.

\section{Rehabilitación pulmonar (RR)}

La RR está indicada en pacientes portadores de EPC que a pesar de un óptimo manejo médico, persisten sintomáticos. Su incorporación como estrategia adicional al manejo convencional, se basa en síntomas, no en el deterioro fisiológico de las pruebas de función pulmonar. Existe poca experiencia en niños portadores de BO post-viral; sin embargo, existen estudios preliminares que sugieren su beneficio. La RR ha sido recomendada como estrategia para el manejo de niños con antecedentes de BO post infecciosa.

\section{Entrenamiento físico general (EFG)}

Se recomienda un EFG con ejercicios aeróbicos, supervisado, al menos 3 veces/semana por un mínimo de 30 minutos. Para planificar el EFG, se debe evaluar la capacidad de realizar ejercicio actual de cada paciente; para lo cual, puede realizarse un test de marcha de 6 minutos (TM6). El test de carga incremental (TCI) permite llevar al paciente desde un estado de reposo físico a su máxima capacidad de trabajo, de manera paulatina y controlada. Puede ser ejecutado en treadmill o en un cicloergómetro, siendo el primero el más recomendado. Al llegar a inclinación de $14 \%$, se empieza a realizar un incremento de la velocidad en $0,5 \mathrm{~km} / \mathrm{h}$ cada un

Tabla 5. Criterios de detención de Prueba de Carga Incremental

- Dolor torácico sugerente de isquemia

- Alteración ECG

- Hipertensión arterial grave

- Desaturación $<90 \%$

- Palidez repentina

- Pérdida de la coordinación

- Confusión mental

- Disnea y/o fatiga

- Frecuencia cardíaca límite (90\% de teórica) minuto, hasta que se cumplan los criterios de detención del test (Tabla 5).

La carga máxima de ejercicio será el máximo valor de pendiente y velocidad logrado durante un minuto completo. Este valor será utilizado como la máxima capacidad de realizar ejercicio y a partir de éste se planificará el entrenamiento más adecuado para cada paciente. Una vez obtenida la carga máxima, es imprescindible, realizar un test de carga constante (TCC) en el ergómetro que utilizaremos para entrenar al paciente, empleando un alto porcentaje de la carga máxima alcanzada en el test de cargas incrementales (70-80\%). Los test de carga constante son más sensibles para evaluar la respuesta al entrenamiento físico $u$ otras intervenciones terapéuticas. Este tipo de pruebas permite evaluar el tiempo que el sujeto es capaz de mantener la carga preestablecida junto con otras variables fisiológicas. Debe monitorizarse $\mathrm{SpO}_{2}$ y frecuencia cardíaca (idealmente con sistema inalámbrico), utilizando $\mathrm{O}_{2}$ suplementario si durante los test de evaluación preliminar presentó desaturaciones (inferior a 90\%). Existen distintos tipos de EFG, sin embargo, el más recomendable es el interválico, donde se aplican cargas de $50 \%$ y $80-90 \%$ de la carga máxima de trabajo de forma alternada cada 2 minutos hasta completar, idealmente, un tiempo de 30 minutos de alta carga (80-90\%) (Figura 4).

La periodicidad sugerida de este tipo de entrenamiento es 2-3 veces a la semana. A la sexta semana se debe realizar una nueva evaluación de TM6 y TCI para establecer nuevas cargas de trabajo y reprogramar el entrenamiento, si fuera necesario. El EFG, no supervisado fuera de instituciones, carece del control de variables clínicas y de asesoramiento de exigencias. Es una alternativa para pacientes menos complejos. Se puede emplear la marcha, natación, camas elásticas, entre otros. Otra alternativa es crear un plan mixto que incluya evaluaciones periódicas en instituciones y EFG tanto fuera, como dentro de instituciones.

\section{Entrenamiento Muscular Respiratorio (EMR)}

En niños existe escasa evidencia de EMR; $\sin$ embargo, en niños con BO su beneficio ha sido demostrado en estudios chilenos. Sugerimos realizar EMR en niños con BO con presión inspiratoria máxima (PIM) o presión espiratoria máxima (PEM) inferiores a $60 \mathrm{cmH}_{2} \mathrm{O}$ y/o que se encuentren bajo el límite inferior de los valores de referencia según edad y sexo de Szeinberg ${ }^{154}$ (Tabla 6). Iniciar con cargas de un $30 \%$ de 


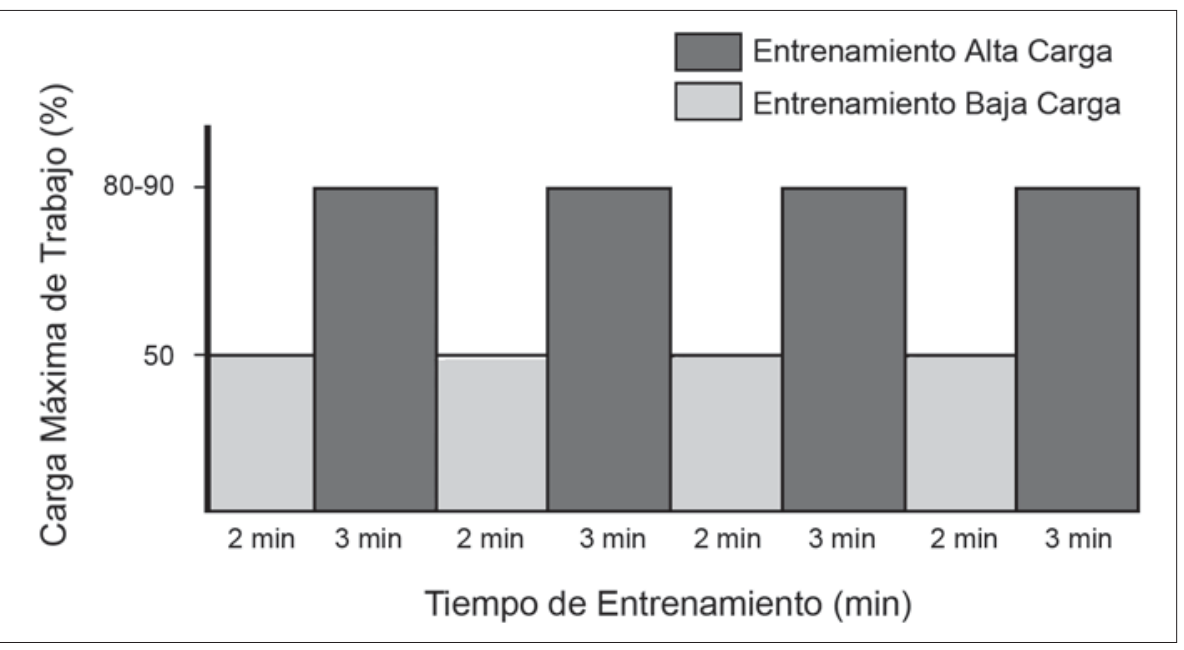

Figura 4. Entrenamiento interválico recomendado. Ver descripción en el texto.

PIM y/o PEM. Recomendamos un sistema tipo intervalo o en series, de duración progresiva y con un período de descanso interseries no mayor a dos minutos. Sugerimos iniciar con 3 series de 3 minutos, con dos minutos de descanso entre cada serie. Cuando el paciente logre tolerar adecuadamente el esquema anterior, aumentar el tiempo de sobrecarga y el número de series hasta lograr las 4 series de 5 minutos de entrenamiento. Controlar presiones máximas en boca, a la segunda semana y luego mensualmente, durante las fases de mejoría de presiones máximas en boca, para aumentar gradualmente la carga y el tiempo de trabajo, siempre

Tabla 6. Valores de presión inspiratoria máxima (PIM) y de presión espiratoria máxima (PEM) según edad y sexo ${ }^{159}$

\begin{tabular}{lccc}
\hline Edad & $\begin{array}{c}\text { Talla } \\
(\mathbf{c m})\end{array}$ & $\begin{array}{c}\text { PIM } \\
\left(\mathbf{c m} \mathbf{H}_{2} \mathbf{O}\right)\end{array}$ & $\begin{array}{c}\text { PEM } \\
\left(\mathbf{c m ~ H _ { 2 }} \mathbf{O}\right)\end{array}$ \\
\hline $\begin{array}{c}\text { Hombres } \\
8-10,9\end{array}$ & $136 \pm 7$ & $116 \pm 26$ & $142 \pm 25$ \\
$11-13,9$ & $151 \pm 10$ & $130 \pm 16$ & $176 \pm 24$ \\
$14-16,9$ & $172 \pm 8$ & $126 \pm 22$ & $166 \pm 44$ \\
$17-20,9$ & $179 \pm 6$ & $143 \pm 12$ & $204 \pm 37$ \\
$21-40$ & $180 \pm 7$ & $123 \pm 12$ & $242 \pm 41$ \\
& & & \\
Mujeres & & & \\
$8-10,9$ & $139 \pm 7$ & $104 \pm 20$ & $129 \pm 29$ \\
$11-13,9$ & $154 \pm 7$ & $112 \pm 20$ & $138 \pm 31$ \\
$14-16,9$ & $162 \pm 6$ & $109 \pm 21$ & $135 \pm 29$ \\
$17-20,9$ & $164 \pm 7$ & $107 \pm 25$ & $138 \pm 33$ \\
$21-40$ & $163 \pm 8$ & $91 \pm 20$ & $143 \pm 36$ \\
\hline
\end{tabular}

en relación al 30\% de la PIM y/o PEM. En caso que el paciente no tolere las exigencias progresivas de cargas y tiempos, disminuir estas exigencias.

Una vez que se inicie el EMR, este debe mantenerse en el tiempo, con el objetivo de mantener una adecuidad física óptima de la bomba muscular respiratoria, y de esta forma aumentar la capacidad funcional ventilatoria frente a eventos de descompensación respiratoria. Cada paciente debe contar con una pauta de entrenamiento diseñada en forma individual, donde se registrarán: la metodología, exigencias (días, cargas y tiempos) y factores que pudiesen haber afectado el proceso de entrenamiento.

\section{Consideraciones sobre $\mathrm{O}_{2}$ en domicilio}

La utilización de $\mathrm{O}_{2}$ suplementario puede ser durante las 24 horas del día o solamente durante los períodos de sueño. Se recomienda la certificación de la $\mathrm{SpO}_{2}$ durante el ejercicio, la comida $\mathrm{y}$ el sueño. La determinación del $\mathrm{pH}, \mathrm{PaO}_{2}$, $\mathrm{PaCO}_{2}$ y $\mathrm{SpO}_{2}$ en una muestra de sangre arterial y su evaluación a través de un analizador de gases en sangre es el mejor método para determinar los niveles de oxígeno sanguíneo al menos una vez/año. Una vez instaurada la oxígenoterapia crónica, el método de elección para el monitoreo de la oxigenoterapia domiciliaria es la $\mathrm{SpO}_{2}$. Los requerimientos de $\mathrm{O}_{2}$ no deben exceder los $2 \mathrm{~L} / \mathrm{m}$ (cánula nasal). Este aporte de $\mathrm{O}_{2}$ debe ser el necesario para lograr una $\mathrm{SpO}_{2}$ mínima de $93 \%$. Se debe realizar un registro de $\mathrm{SpO}_{2}$ simple, en períodos de actividad y sueño, que demuestren $\mathrm{SpO}_{2}<93 \%$ y que coincidan con aumento de frecuencia respiratoria y frecuencia cardíaca de por lo menos $15 \%$ sobre la 
condición basal del paciente. Si se cuenta con una $\mathrm{SpO}_{2}$ continua, el registro debe tener una duración de 8-12 horas, con menos del 20\% del tiempo de registro ocupado por desconexiones y artefactos, que muestre al menos uno de los siguientes puntos: a) $\mathrm{SpO}_{2}$ promedio $<93 \%$, más del $10 \%$ del tiempo total de registro saturando $<93 \%$; b) desaturaciones $<85 \%$ de más de 10 segundos de duración, (aunque sea sólo un episodio, si se verifica que es real y no artefacto); c) si el niño es mayor de dos años, desaturaciones $<85 \%$ de menos de 10 segundos de duración.

\subsection{Fuentes de $\mathrm{O}_{2}$ disponibles}

1. $\mathrm{O}_{2}$ líquido.

2. Cilindro de $\mathrm{O}_{2}$ gaseoso.

3. Concentrador de $\mathrm{O}_{2}$.

\subsection{Elección de la fuente de $\mathrm{O}_{2}$}

1. Si es un paciente en edad escolar, que requiere autonomía para deambular y reintegrarse a clases, se elegirá $\mathrm{O}_{2}$ líquido.

2. Si es un paciente que no deambula, pero utiliza flujos menores o iguales a 1 litro por minuto, deberá usar cilindro de $\mathrm{O}_{2}$ gaseoso.

3. Si el paciente no deambula, pero requiere un flujo de $\mathrm{O}_{2}$ entre 1 y 2 litros por minuto, el sistema elegido será concentrador de $\mathrm{O}_{2}$.

\section{Miscelánea}

\section{Preparación para cirugía de tórax}

Todo paciente considerado candidato quirúrgico debe tener una $\mathrm{CT}$ de alta resolución (HRCT) durante los últimos 12 meses. Se requiere de apoyo institucional para kinesiterapia pre y post-operatoria. Es necesario tener un cultivo de esputo para la evaluación antibiótica apropiada profiláctica. Las preocupaciones en torno a CPT, CRF, post-lobectomía no son pertinentes en estos pacientes, dado que habitualmente el segmento pulmonar a ser resecado es completamente disfuncionante y no aporta con hematosis efectiva, sino más bien actúa como shunt; por ello algunos equipos quirúrgicos solicitan cintigrama V/Q previo a la cirugía resectiva, para certificar que el segmento a resecar no es funcional. La resección pulmonar en estos casos, debe plantearse lo más precozmente posible.

\section{Soporte ventilatorio no invasivo en domicilio}

No existen reportes de la utilidad de la asistencia con VNI en pacientes con $\mathrm{BO}$; sin embargo, en Chile desde el inicio del Programa
AVNI se ha utilizado en niños con BO post-viral con insuficiencia respiratoria crónica hipercápnica. La evaluación requerida incluye:

a. Índices de función pulmonar: espirometría y curva flujo volumen.

b. Evaluación de fuerza muscular: presión inspiratoria máxima (PIM) y presión espiratoria máxima (PEM), ventilación voluntaria máxima (VVM), peak flow de tos (flujo cúspide de tos), evaluación de la fatigabilidad o resistencia de la musculatura respiratoria a través del tiempo límite (Tlim) y de la capacidad del desempeño físico (fitness) con el test de marcha de 6 minutos.

c. Estudios durante el sueño: $\mathrm{SpO}_{2}$ de 8-12 horas, PSG o poligrafía.

d. Monitorización del intercambio gaseoso: Gasometría arterial o venosa, $\mathrm{SpO}_{2}$ diurna y nocturna, capnografía o registro de $\mathrm{PCO}_{2}$ transcutánea $\left(\mathrm{PtCO}_{2}\right)$.

Los criterios de selección utilizados son:

a. Hipoventilación nocturna pesquisada a través de $\mathrm{SpO} 2\left(\mathrm{SpO}_{2}<90 \%\right.$ por más de $10 \%$ del tiempo de sueño).

b. Gasometría arterial con $\mathrm{PaCO}_{2}>50 \mathrm{mmHg}$, exceso de base $(\mathrm{EB})>4 \mathrm{mEq} / \mathrm{L}$.

c. Espirometría con trastorno ventilatorio restrictivo severo (CVF $<50 \%$ valor predicho) o debilidad de la musculatura respiratoria (PIM y/o PEM $<40 \mathrm{cmH}_{2} \mathrm{O}$, peak flow $<150-200 \mathrm{~L} / \mathrm{min})$.

\subsection{Elección de la modalidad ventilatoria}

Existe poca evidencia que sugiera la modalidad de AVNI en distintas patologías crónicas. Se utiliza la mejor tolerada por el paciente. La asistencia con VNI en domicilio se entrega generalmente a través de una mascarilla nasal y $\mathrm{O}_{2}$ para aliviar la hipoventilación nocturna. En la insuficiencia respiratoria crónica reagudizada, se prefiere el BiPAP en su modo $\mathrm{S} / \mathrm{T}$ o $\mathrm{P} / \mathrm{C}$, con la que se logra mejorar la ventilación minuto, la frecuencia respiratoria y la gasometría arterial.

\section{Cuidados paliativos/terminales}

Resulta difícil definir clínicamente el estadio terminal de una enfermedad. La valoración clínica y de laboratorio debe estar en manos de personal experimentado que pueda establecer sin dudas algunos parámetros de irreversibilidad. El eje debe ser siempre el paciente, con cuidados lo suficientemente flexibles, en relación directa con la familia. Deben evitarse los tratamientos innecesarios y cruentos, siendo la prioridad calmar el dolor y controlar los síntomas. La familia 
deberá estar muy bien informada, pues la mayoría de los pacientes con $\mathrm{BO}$ fallecen por insuficiencia respiratoria. La VNI por largo tiempo, debe ser recomendada en aquellos pacientes con un claro beneficio en la sobrevida y/o calidad de sueño.

\section{Bibliografía}

1.- ABRAMS S A. Chronic Pulmonary Insufficiency in children and its effects on growth and development. J Nutr 2001; 131: 938s-41s.

2.- AMBROSINO N, VAGHEGGINI G. Noninvasive positive pressure ventilation in the acute care setting: where are we? Eur Respir J 2008; 31: 874-86.

3.- AMERICAN ACADEMY OF PEDIATRICS, Committee on Hospital Care and Section on Critical Care and Society of Critical Care Medicine, Pediatric Section Admission Criteria Task Force. Guidelines for Developing Admission and Discharge Policies for the Pediatric Intensive Care Unit. Pediatrics 1999; 103; 840-2.

4.- AMERICAN THORACIC SOCIETY, European Respiratory Society. ATS/ERS statement on pulmonary rehabilitation. Am J Respir Crit Care Med 2006; 173: 1390-413.

5.- ANDREASSON B, JONSON B, KORNFALT R, NORDMARK E, SANDSTROM S. Long-term effects of physical exercise on working capacity and pulmonary function in cystic fibrosis. Acta Paediatr Scand 1987; 76: 70-5.

6.- ARCE J. Secuelas post-infección por adenovirus: evaluación por tomografía computada. Rev Chil Radiol 2002; 8: 154-66.

7.- $\quad$ ASHER M I, PARDY R L, COATES A L, THOMAS E, MACKLEM P T. The effect of inspiratory muscle training in patients with cystic fibrosis. Am Rev Respir Dis 1982; 126; 855-9.

8.- ATS/ACCP Statement on Cardiopulmonary Exercise Testing. Am J Respir Crit Care Med 2003; 167: 211 77.

9.- $\quad$ ATS statement: guidelines for the six-minute walk test. Am J Respir Crit Care Med 2002; 166: 111-7.

10.- AVITAL A, SPRINGER CH, BAR-YISHAY E, GODFREY S. Adenosine, methacholine, and exercise in children with asthma or paediatric chronic obstructive pulmonary disease. Thorax 1995; 50: 511 6.

11.- BALFOUR-LYNN I M. Domiciliary Oxygen for Children. Pediatr Clin North Am 2009; 56: 275-96.

12.- BALFOUR-LYNN I M, PRIMHAK R A, SHAW B N. Home oxygen for children: who, how and when? Thorax 2005; 60: 76-81.

13.- BAR-OR O. Pediatric sports medicine for the practitioner. New York, NY: McGraw-Hill, 1983.

14.- BARJA S. Nutrición en enfermedades crónicas respi- ratorias infantiles. Capítulo 42. En: Enfoque clínico de las Enfermedades Respiratorias del Niño. Autores: Sánchez I. y Prado F. Ediciones Universidad Católica de Chile. Enero 2007.

15.- BARKER A. Bronchiectasis. N Engl J Med 2002; 346: 1383-93.

16.- BATTISTI A, TASSAUX D, JANSSENS J P, MICHOTTE J B, JABER S, JOLLIET P. Performance characteristics of 10 home mechanical ventilators in pressure-support mode: a comparative bench study. Chest 2005; 127: 1784-92.

17.- BECROFT D M. Bronchiolitis obliterans, bronchiectasis, and other sequelae of adenovirus type 21 infection in young children. J Clin Pathol 1971; 24: 72-82.

18.- BISGAARD H, KLUG B. Lung function measurement in awake young children. Eur Respir J 1995; 8: 2067 75.

19.- BOSA V L, MELLO E D, MOCELIN H T, BENEDETTI F J, FISCHER G B. Assessment of nutritional status in children and adolescents with post-infectious bronchiolitis obliterans. J Pediatr (Rio J) 2008; 84: 323-30.

20.- BRAGGION C, CORNACCHIA M, MIANO A, SCHENA F, VERLATO G, MASTELLA G. Exercise tolerance and effects of training in young patients with cystic fibrosis and mild airway obstruction. Pediatr Pulmonol 1989; 7: 145-52.

21.- BRITISH THORACIC SOCIETY. Statement Pulmonary Rehabilitation. Thorax 2001; 56: 827-34.

22.- CARLSON B A, SWENSEN S J, O’CONNELL E J, EDELL E S. High-resolution computed tomography for obliterative bronchiolitis. Mayo Clin Proc 1993; 68: $307-8$.

23.- CASTRO-RODRÍGUEZ J A, DASZENIES C, GARCÍA M, MEYER R, GONZALES R. Adenovirus pneumonia in infants and factors for developing bronchiolitis obliterans: a 5-year follow-up. Pediatr Pulmonol 2006; 41: 947-53.

24.- CAZZATO S, POLETTI V, BERNARDI F, LORONI L, BERTELLI L, COLONNA S, et al. Airway inflammation and lung function decline in childhood postinfectious bronchiolitis obliterans. Pediatric Pulmonology 2008; 43: 381-90.

25.- CERNY F. Relative effects of bronchial drainage and exercise for in-hospital care of patients with cystic fibrosis. Phys Ther 1989; 69: 633-39.

26.- COLBY T V. Bronchiolitis. Pathologic considerations. Am J Clin Pathol 1998; 109: 101-9.

27.- COUlTAS D B, SAMET J M, BUTLER C. Bronchiolitis obliterans due to Mycoplasma pneumoniae. West J Med 1986; 144: 471-4.

28.- COLOM A J, TEPER A M, VOLLMER W M, DIETTE G B. Risk factors for the development of bronchiolitis obliterans in children with bronchiolitis. Thorax 2006; 61: 503-6. 
29.- COLOM A J, MAFFEY A F, NAVARRA F, TEPER A. Pulmonary function in children with post-viral chronic pulmonary disease (PCPD). In: ATS International Conference 2002; Atlanta; p. A159 (Abstract).

30.- COLOM A J, NAVARRA F, KOFMAN C, TEPER A. Respiratory mechanics in children with post-viral chronic pulmonary disease (PCPD). Am J Respir Crit Care Med 2002; 163: A159. (Abstract).

31.- COLOM A J, TEPER A M. Postinfectious bronchiolitis obliterans. Arch Argent Pediatr 2009; 107: 160-7.

32.- Consenso de oxígenoterapia domiciliaria en pediatría. Arch Argent Pediatr 2005; 103: 535-44.

33.- COPLEY S J, PADLEY S P. High-resolution CT of paediatric lung disease. Eur Radiol 2001; 11: 256475.

34.- COSTA C L, SPILBORGHS G M, MARTINS M A, SALDIVA P H, MAUAD T. Nitric acid-induced bronchiolitis in rats mimics childhood Bronchiolitis obliterans. Respiration 2005; 72: 642-9.

35.- COSTA M L, STEIN R T, BAUER M E, MACHADO D C, JONES M H, BERTOTTO C, et al. Levels of Th1 and Th2 cytokines in children with postinfectious bronchiolitis obliterans. Ann Trop Paediatr 2005; 25: 261-6.

36.- CHAN P W, MURIDAN R, DEBRUYNE J A. Bronchiolitis obliterans in children: clinical profile and diagnosis. Respirology 2000; 5: 369-75.

37.- CHANG A, MASEL J, MASTERS B. Post-infectious bronchiolitis obliterans: clinical, radiological and pulmonary function sequelae. Pediatr Radiol 1998; 28: 23-9.

38.- CHIH-YUNG CHIU, KIN-SUN WONG, YHUCHERING HUANG, TZOU-YIEN LIN. Bronchiolitis obliterans in children: Clinical presentation, therapy and long-term follow-up. J Paediatrics and Child Health 2008; 44: 129-33.

39.- CHUANG Y Y, CHIU C H, WONG K S, HUANG J G, HUANG Y C, CHANG L Y, LIN T Y. Severe adenovirus infection in children. J Microbiol Immunol Infect 2003; 36: 37-40.

40.- CHOI S J, CHOI B K, KIM H J, LEE S H, CHOI S H, PARK S J, et al. Lateral decubitus HRCT: a simple technique to replace expiratory CT in children with air trapping. Pediatr Radiol 2002; 32: 179-82.

41.- DE MEER G, HEEDERIK D, POSTMA D S. Bronchial responsiveness to adenosine 59-monophosphate (AMP) and methacholine differ in their relationship with airway allergy and baseline $\mathrm{FEV}_{1}$. Am J Respir Crit Care Med 2002; 165: 327-31.

42.- DELLON E, DONALDSON S, JOHNSON R, DAVIS S. Safety and tolerability of inhales hypertonic saline in young children with cystic fibrosis. Pediatr Pulmonol 2008; 43: 1100-6.

43.- DONALDSON S. Hydrator therapies for cystic fibro- sis lung disease. Pediatr Pulmonol 2008; 43: S18S23.

44.- DOSANJH A. Unilateral bronchiolitis obliterans: a case report. Clin Pediatr (Phila) 1992; 31: 319-20.

45.- DUMAS C, SKAFF C, JUST J, TOUNIAN P, FONTAINE J L, GRIMFELD A, et al. Body composition of children with chronic Lung Disease. Pediatr Pulmonol 1997; 16: 174-6.

46.- EDLUND L D, FRENCH R W, HERBST J J, RUTTENBURG H D, RUHLING R O, ADAMS T D. Effects of a swimming program on children with cystic fibrosis. Am J Dis Child 1986; 140: 80-3.

47.- ENG P A, MORTON J, DOUGLASS J A, RIEDLER J, WILSON J, ROBERTSON C F. Short-term efficacy of ultrasonically nebulized hypertonic saline in cystic fibrosis. Pediatr Pulmonol 1996; 21: 77-83.

48.- EPLER G R. Bronchiolar disorders with airflow obstruction. Curr Opin Pulm Med 1996; 2: 134-40.

49.- ESSOURI S, CHEVRET L, DURAND P, HAAS V, FAUROUX B, DEVICTOR D. Noninvasive positive pressure ventilation: five years of experience in a pediatric intensive care unit. Pediatr Crit Care Med 2006; 7: 329-34.

50.- FAUROUX B, LOFASO F. Domiciliary non-invasive ventilation in children. Rev Mal Respir 2005; 22: 289-303.

51.- FAUROUX B, LOFASO F. Non-invasive mechanical ventilation: when to start for what benefit? Thorax 2005; 60: 979-80.

52.- FAROUX B, PIGET J, POLKEY M, ISABEY D, CLEMENT A, LOFASO F. In vivo physiologic comparison of two ventilators used for domiciliary ventilation in children with cystic fibrosis. Crit Care Med 2001; 29: 2097-105.

53.- FISHER G B, TEPER A M, COLOM A J. Acute viral bronchiolitis and its sequel in developing countries. Paediatrics Respiratory Rev 2002; 3: 298-302.

54.- FORTENBERRY J D, DEL TORO J, JEFFERSON L S, EVEY L, HAASE D. Management of pediatric acute hipoxemic respiratory insufficiency with bilevel positive pressure (BIPAP) nasal mask ventilation. Chest 1995; 108: 1059-64.

55.- FULLMER J J, FAN L L, DISHOP M K, RODGERS C, KRANCE R. Successful treatment of bronchiolitis obliterans in a bone marrow transplant patient with tumor necrosis factor alpha blockade. Pediatrics 2005; 116: 767-70.

56.- GAILLARD E. Reversible bronchial dilatation in children: comparison of serial high-resolution computer tomography scans of the lungs. Eur J Radiol 2003; 47: 215-20.

57.- GARROD R. Role of physiotherapy in the management of chronic lung diseases: an overwiew od systematic reviews. Resp Med 2007; 101: 249-56.

58.- GEIGER R, STRASAK A, TREML B, GASSER K, KLEINSASSER A, FISCHER V, et al. Six-minute walk 
test in children and adolescents. J Pediatr 2007; 150: 395-9.

59.- GERHARDT S G, MCDYER J F, GIRGIS R E, CONTE J V, YANG S C, ORENS J B. Maintenance azithromycin therapy for bronchiolitis obliterans syndrome: results of a pilot study. Am J Respir Crit Care Med 2003; 168: 121-5.

60.- GIBSON P G. Sputum induction in children. Eur Respir J 2002; 20: 44s-46s.

61.- GIBSON P G, HENRY R L, THOMAS P. Noninvasive assessment of airway inflammation in children: induced sputum, exhaled nitric oxide, and breath condensate. Eur Respir J 2000; 16: 1008-15.

62.- GIRARDET J, VIOLA S. Nutrition and severe chronic respiratory diseases: pathophysiologic mechanisms. Pediatr Pulmonol 2001; s23: 20-21.

63.- GODGFREY S, SPRINGER C, NOVISKI N, MAAYAN CH, AVITAL A. Exercise but not methacholine differenciates astma from chronic lung disease in children. Thorax 1991; 46: 488-92.

64.- GODFREY S. Pulmonary hemorrhage/hemoptysis in children. Pediatr Pulmonol 2004; 37: 476-84.

65.- Grupo de trabajo de la SEPAR. Pruebas de ejercicio cardiopulmonar. Arch Bronconeumología 2001; 37: 247-68.

66.- Guía de Organización y Funcionamiento de Unidades de Pacientes Críticos Pediátricos (UPC). Rama de Intensivos Pediátricos, Sociedad Chilena de Pediatría. Ministerio de Salud de Chile. 2006.

67.- HACKEN N. Bronchiectasis. Clin Evid 2006; 15: 19.

68.- HANSELL D M. Small airways diseases: detection and insights with computed tomography. Eur Respir J 2001; 17: 1294-313.

69.- HAGGERTY M C, JONES P. Clinically meaningful outcomes in patients with chronic obtructive pulmonary disease. Am J Med 2004; 117 (Suppl 12A): 49S-59S.

70.- HARDY K A. Childhood bronchiolitis obliterant. In: Epler GR, Editor. Disease of Bronchioles. New York: Raven Press Ltd 1994, p 415-26.

71.- HARDY K A, SCHIDLOW D V, ZAERI N. Obliterative bronchiolitis in children. Chest 1988; 93: 4606.

72.- HESS D R. The evidence for noninvasive positivepressure ventilation in the care of patients in acute respiratory failure: a systematic review of the literature. Respir Care 2004; 49: 810-29.

73.- HIRSCHHEIMER M, SILVA P S, GIUDICI R, CARRILHO M, MAUAD T, ISHIDA M. Simultaneous viral infection and childhood bronchiolitis obliterans. Braz J Infect Dis 2002; 6: 146-8.

74.- HO S A, BALL R, MORRISON L J, BROWNLEE K G, CONWAY S P. Clinical value of obtaining sputum and cough swab samples following inhaled hypertonic saline in children with cystic fibrosis. Pediatr
Pulmonol 2004; 38: 82-7.

75.- HODGES I G, MILNER A D, GROGGINS R C, STOKES G M. Causes and management of bronchiolitis with chronic obstructive features. Arch Dis Child 1982; 57: 495-9.

76.- HODSON M, MADDEN B, STEVEN M, TSANG V, YACOUB M. Non-invasive mechanical ventilation for cystic fibrosis patients-a potential bridge to transplantation. Eur Respir J 1991; 4: 524-7.

77.- HUMAN ENERGY REQUIREMENTS. Report of a join $\mathrm{FAO} / \mathrm{WHO} / \mathrm{UNU}$ Expert Consultation. Rome, 17-24 October, 2001. FAO, Food and Nutrition Technical Report Series.

78.- JAIMOVICH D. Admission and discharge guidelines for the pediatric patient requiring intermediate care. Crit Care Med 2004; 32: 1215-18.

79.- JENSEN S P, LYNCH D A, BROWN K K, WENZEL $S$ E, NEWELL J D. High-resolution CT features of severe asthma and bronchiolitis obliterans. Clin Radiol 2002; 57: 1078-85.

80.- JONES M H, PITREZ P M, STEIN R T. PostInfectious Bronchiolitis Obliterans. Pediatr Pulmonol Suppl 2004; 26: 64-5.

81.- KALENGA M. Lung growth and development during experimental malnutrition. Pediatr Pulmonol 1997; s16: 165-6.

82.- KARADAG B. Non-Cistyc-Fibrosis Bronchiectasis in Children: A Persistent problem in developing countries. Respiration 2005; 72: 233-38.

83.- KEENS T G, KRASTINS I R, WANNAMAKER E M, LEVISON H, CROZIER D N, BRYAN A C. Ventilatory muscle endurance training in normal subject end patients in cystic fibrosis. Am Rev Respir Dis 1977; 116: 853.

84.- KESSON. Respiratory virus infection. Paediatric Respiratory Rev 2007; 8: 240-248.

85.- KIM C, KIM S, KIM J, KOH Y, COHEN A, DETERDING R R, et al. Bronchiolitis obliterans in the 1990s in Korea and the United States. Chest 2001; 120: 1101-6.

86.- KIM M J, LEE K Y. Bronchiolitis obliterans in children with Stevens-Johnson syndrome: follow-up with high resolution CT. Pediatr Radiol 1996; 26: 22-5.

87.- KIM D K, YOO Y, YU J, CHOI S H, KOH Y Y. Bronchial responsiveness to methacholine and adenosine 5'-monophosphate (AMP) in young children with post-infectious bronchiolitis obliterans. Acta Paediatrica 2006; 95: 56-61.

88.- KING P. Is there a role for inhaled corticosteroids and macrolide therapy in bronchiectasis? Drugs 2007; 67: 965-74.

89.- KLUG B, BISGAARD H. Measurement of lung function in awake 2-4 years old asthmatic children during methacholine challenge and acute asthma. Pediatr Pulmonol 1996; 21: 290-300. 
90.- KOH Y Y. Bronchoalveolar cellularity and interleukin-8 levels in measles bronchiolitis obliterans. Chest 2007; 131: 1454-60.

91.- KOH Y Y, JUNG D E, KOH J Y, KIM J Y, YOO Y, KIM C K. Bronchoalveolar cellularity and interleukin8 levels in measles bronchiolitis obliterans. Chest 2007; 131: 1454-60.

92.- KRASINSKI K. Severe respiratory syncytial virus infection: clinical features, nosocomial acquisition and outcome. Pediatr Infect Dis 1985; 4: 250-7.

93.- KURLAND G, MICHELSON P. Bronchiolitis obliterans in children. Pediatr Pulmonol 2005; 39 : 193-208.

94.- LARAYA-CUASAY L R, DEFOREST A, HUFF D, LISCHNER H, HUANG N N. Chronic pulmonary complications of early influenza virus infection in children. Am Rev Respir Dis 1977; 116: 617-25.

95.- LEITH D, BRADLEY M. Ventilatory muscle strength and endurance training. J Appl Physiol 1976; 41: 508.

96.- LELlouche F, MAGGiore S M, DEYE N, TAILLÉ S, PIGEOT J, HARF A, et al. Effect of the humidification device on the work of breathing during noninvasive ventilation. Intensive Care Med 2002; 28: 1582-9.

97.- LEONG M A, NACHAJON R, RUCHELLI E, ALLEN J L. Bronchitis obliterans due to Mycoplasma pneumonia. Pediatr Pulmonol 1997; 23: 375-81.

98.- LI A M, YIN J, AU J T, SO H K, TSANG T, WONG E, et al. Standard reference for the 6-minute walk test in healthy children aged 7 to 16 years. Am J Respir Crit Care Med 2007; 176: 174-80.

99.- LINARES M, MEYER R, SOTO G. Evaluación de la respuesta broncodilatadora en pacientes secuelados de adenovirus. Rev Chil Pediatr 2004; 75: S37-S44.

100.- LOUGHLIN G, HEIGEN H. Respiratory disease in children, diagnosis and management. Barsky D L, Stallings V A. Nutritional Management in Pediatric Pulmonary disease. Edit. Williams and Wilkins, $1^{\circ}$ Ed, 1994: 813-28.

101.- LOBO AL, GUARDIANO M, NUNES T, AZEVEDO I, VAZ L G. Pos-infectious bronchiolitis obliterans in children. Rev Port Pneumol 2007; 13: 495-509.

102.- LÖTTERS F, VAN TOL B, KWAKKEL G, GOSSELINK R. Effects of controlled inspiratory muscle training in patients with COPD: a metaanalysis. Eur Respir J 2002; 20: 570-6.

103.- LYNCH D A, HAY T, NEWELL J D Jr, DIVGI V D, FAN L L. Pediatric diffuse lung disease: diagnosis and classification using high-resolution CT. AJR Am J Roentgenol 1999; 173: 713-8.

104.- MAFFEY A F, COLOM A J, KOFMAN C D, VIDAUMETA S M, TEPER A M. Longitudinal Study of pulmonary function in infants with postviral chronic pulmonary disease. Am J Respir Crit Care Med 1996; 4: A153 (Abstract).
105.- MAGDE S, BRYON M. A model for transition from pediatric to adult care in cystic fibrosis. J Pediatr Nurs 2002; 17: 283-8.

106.- MANCUSO M, PACCHIONI D, RUFFINI E, CAVALLO A, FILOSSO P, VIALE A, et al. Successful bilateral lung volume reduction in a child with emphysema from bronchiolitis obliterans. J Thorac Cardiovasc Surg 2004; 128: 645-7.

107.- MAROSTICA P. Non-Cistyc-Fibrosis Bronchiectasis. A Perspective from South America. Paed Resp Rev 2006; 7: 275-80.

108.- MASSIE R, ARMSTRONG D. Bronchiectasis and bronchiolitis obliterans post respiratory syncytial virus infection: think again. J Paediatr Child Health 1999; 35: 497-8.

109.- MATTIELLO R, SARRIA E E, STEIN R, FISCHER G B, MOCELIN H T, BARRETO S S, et al. Functional capacity assessment during exercise in children and adolescents with post-infectious bronchiolitis obliterans. J Pediatr (Rio J) 2008; 84: 337-43.

110.- MAUAD T, DOLHNIKOFF M; São Paulo Bronchiolitis Obliterans Study Group. Histology of childhood bronchiolitis obliterans. Pediatr Pulmonol 2002; 33: 466-74.

111.- MAUAD T, VAN SCHADEWIJK A, SCHRUMPF J, et al. Lymphocytic inflammation in childhood bronchiolitis obliterans. Pediatr Pulmonol 2004; 38: 233-9.

112.- MEDINA A, PRIETO S, REY M, CONCHA A, MENÉNDEZ S, CRESPO M. Aplicación de la ventilación no invasiva en una Unidad de Cuidados Intensivos Pediátricos. An Pediatr (Barc) 2005; 62: 13-9.

113.- MEHTA S, HILL N S. Noninvasive Ventilation. Am J Respir Crit Care Med 2001; 163: 540-77.

114.- MEYER B, DE BLIC J, PARIENTE D, LAMOUR C, BENOIST M R, NEZELOF C, et al. Bronchiolitis obliterans: investigation and diagnosis. Ann Pediatr (Paris) 1983; 30: 351-5.

115.- MILLER A. Guidelines for the management of spontaneous pneumothorax. Brit Med J 1993; 307: 114-6.

116.- MINSAL. Estadísticas nutricionales, Plan Nacional de Alimentación Complementaria (PNAC) del prematuro extremo y displasia broncopulmonar del prematuro: Guías clínicas MINSAL. www.minsal.cl

117.- MISTCHENKO A S, DIEZ R A, MARIANI A L, ROBALDO J, MAFFEY A F, BAYLEY-BUSTAMANTE G, et al. Cytokines in adenoviral disease in children: association of interleukin-6, interleukin-8, and tumor necrosis factor alpha levels with clinical outcome. J Pediatr 1994; 124: 714-20.

118.- MISTCHENKO A S, KOCH E R R, KAJON A E, TIBALDI F, MAFFEY A F, DIEZ R A. Lymphocyte subsets and cytokines in adenoviral infection in children. Acta Paediatr 1998; 87: 933-9.

119.- MOCELIN H, FISCHER G, IRIAR K, CUNHA L. 
Evaluación clínica y funcional de niños con bronquiolitis obliterante post-infecciosa con seguimiento a largo plazo. Rev Chil Pediatr 2004; 75 (Supl): S12-7.

120.- MOONNUMAKAL S P, FAN L L. Bronchiolitis obliterans in children. Current Opinion in Pediatrics 2008, 20: 272-8.

121.- MURTAGH P, GIUBERGIA V, VIALE D, BAUER G, PENA $\mathrm{H}$ G. Lower respiratory infections by adenovirus in children. Clinical features and risk factors for bronchiolitis obliterans and mortality. Pediatr Pulmonol 2009; 44: 450-6.

122.- MUTHALITAS K. Improvement in health status following bonchopulmonary hygiene physical therapy in patients with bronchiectasis. Resp Med 2008; 102: 1140-44.

123.- NICOLAI T. Pediatric Bronchoscopy. Pediatric Pulmonol 2001; 31: 150-64.

124.- NIXON P A, JOSWIAK M L, FRICKER F J. A sixminute walk test for assessing exercise tolerance in severely ill children. J Pediatr 1996; 129: 362-6.

125.- NIXON P A, ORENSTEIN D M, KELSEY S F, DOERSHUK C F. The prognostic value of exercise testing in patients with cystic fibrosis. N Engl J Med 1992; 327: 1785-8.

126.- Norma Programa Nacional de Oxígeno Ambulatorio. Minsal, 2003.

127.- NORREEGAARD O. Non-invasive ventilation in acute respiratory failure in children. En: Non-invasive respiratory Support. Simonds AK. Third edition, Edward Arnold (Publishers) Ltd. 2007; 257-73.

128.- NORREGAARD O. Noninvasive ventilation in children. Eur Respir J 2002; 20: 1332-42.

129.- NORZILA M Z, AZIZI B H, NORRASHIDAH A W, YEOH N M, DENG C T. Home oxygen therapy for children with chronic lung diseases. Med J Malaysia 2001; 56: 151-7.

130.- O'DONNELL A. Bronchiectasis. Chest 2008; 134: 815-23.

131.- O'LONE E. Spontaneous pneumothorax in children: when is invasive treatment indicated? Pediatr Pulmonol 2008; 43: 41-6.

132.- ORENSTEIN D M, HOVELL M F, MULVIHILL M, KEATING K K, HOFSTETTER C R, KELSEY S, et al. Strength $v s$ aerobic training in children with cystic fibrosis: a randomized controlled trial. Chest 2004; 126: 1204-14.

133.- PADLEY S P, ADLER B D, HANSELL D M, MÜLLER N L. Bronchiolitis obliterans: high resolution $\mathrm{CT}$ findings and correlation with pulmonary function tests. Clin Radiol 1993; 47: 23640.

134.- PAIVA R, CAMPOS C, SALINAS P, PRADO F. Asistencia ventilatoria no invasiva: Guía para el manejo de pacientes con insuficiencia respiratoria aguda Neumol Pediatr 2008; 3 (supp1): 45-53.
135.- PENN C C, LIU C. Bronchiolitis following infection in adults and children. Clin Chest Med 1993; 14: 645-54.

136.- PEREIRA G R, BAUMGART S, BENNETT M J, STALLINGS V A, GEORGIEFF M K, HAMOSH M, et al. Use of high-fat formula for premature infants with bronchopulmonary dysplasia: Metabolic, pulmonary, and nutritional studies. J Pediatr 1994; 124: 605-11.

137.- PÉREZ M J, KOGAN R, MAGGI L, MENDOZA C. Seguimiento clínico y factores de riesgo en niños con enfermedades respiratorias por adenovirus. Rev Chil Ped 2007; 78: 261-67.

138.- PRABHU M B, BARBER D, COCKCROFT D W. Bronchiolitis obliterans and Mycoplasma pneumonia. Respir Med 1991; 85: 535-7.

139.- RICARD J D, DREYFUSS D, SAUMON G. Ventilatorinduced lung injury. Eur Respir J 2003; 42 Suppl: 2S9S.

140.- RIES A L, BAULDOFF G S, CASABURI R, MAHLER D A, ROCHESTER C L, HERRERÍAS C; Pulmonary Rehabilitation, Join ACCP/AACVPR Evidence-Based Clinica Practice Guidelines. Chest 2007; 131 (5 Suppl): 4S-42S.

141.- ROEBUCK D. Hemoptysis and bronchial artery embolization in children. Ped Resp Rev 2008; 9: 95 104.

142.- RUSZNIERZ G，COCIGLIO R，PIERINI J, MALATINI M, WALKER A. Arch Argent Pediatr 2007; 105: 216-20.

143.- SÁNCHEZ I, VALENZUELAA, BERTRAND P. Apoyo ventilatorio domiciliario en niños con insuficiencia respiratoria crónica. Experiencia clínica. Rev Chil Pediatr 2002; 73: 51-5.

144.- SAWYER E H, CLANTON T L. Improved pulmonary function and exercise tolerance with inspiratory muscle conditioning in children with cystic fibrosis. Chest 1993; 104: 1490-7.

145.- SAWYER S, ROSIER M, PHELAN P, BOWES G. The self-image of adolescents with cystic fibrosis. J Adolesc Health 1995; 16: 204-8.

146.- SCHLESINGER C, VEERARAGHAVAN S, KOSS M N. Constructive (obliterative) bronchiolitis. Curr Opin Pulm Med 1998; 4: 288-93.

147.- SCHELLHASE D E. Pediatric Flexible airway endoscopy. Curr Opin Pediatr 2002; 14: 327-33.

148.- SCHRAMEL F. Currents aspects of spontaneous pneumothorax. Eur Resp J 1997; 10: 1372-79.

149.- SIBTAIN N A, PADLEY S P. HRCT in small and large airways diseases. Eur Radiol 2004; 14 Suppl 4: L31-43.

150.- SIMILA S, LINNA O, LLANNING P, HEIKKINEN E, ALA-HOUHALA M. Chronic lung damage caused by adenovirus type 7: a ten-year follow-up study. Chest 1981; 80: 127-31.

151.- SILVA J, PUPPO H, VARGAS D, GONZÁLEZ R, 
PAVÓN D, GIRARDI G. Entrenamiento muscular inspiratorio en niños secuelados por adenovirus. Rev Chil Enfer Respir 1999; 15: 239.

152.- SIMONDS A K. Recent advances in respiratory care for neuromuscular disease. Chest 2006; 130: 187986.

153.- SIMONDS A K. Respiratory support for the severely handicapped child with neuromuscular disease: ethics and practicality. Semin Respir Crit Care Med 2007; 28: 342-54.

154.- SLY P D, SOTO-QUIROS M E, LANDAU L I, HUDSON I, NEWTON-JOHN H. Factors predisposing to abnormal pulmonary function after adenovirus type 7 pneumonia. Arch Dis Child 1984; 59: 935-9.

155.- SMITH K J, FAN L L. Insights into post-infectious bronchiolitis obliterans in children. Thorax 2006; 61: 462-63.

156.- SOLWAY S, BROOKS D, LACASSE Y, THOMAS S. A qualitative systemic overview of the measurement properties of functional walk tests used in the cardiorespiratory domain. Chest 2001; 119: 256-70.

157.- SOTO G. Tomografía computada de alta resolución en niños con daño pulmonar crónico por adenovirus: caracterización y correlación con función pulmonar. Rev Chil Radiol 2002; 8: 149-53.

158.- SURI R, MARSHALL L J, WALLIS C, METCALFE C, SHUTE J K, BUSH A. Safety and use of sputum induction in children with cystic fibrosis. Pediatr Pulmonol 2003; 35: 309-13.

159.- SZEINBERG A, MARCOTTE J E, ROIZIN H, MINDORFF C, ENGLAND S, TABACHNIK E, et al. Normal values of maximal inspiratory and expiratory pressures with a portable apparatus in children, adolescents, and young adults. Pediatr Pulmonol 1987; 3: 255-8.

160.- TEPER A M, FISCHER G, JONES M H. Respiratory sequelae of viral diseases: from diagnosis to treatment. J Pediatr (Rio J) 2002; 78 Suppl 2: S187-94.

161.- TEPER A M, KOFMAN C D, MAFFEY A F, VIDARRUETA S M. Lung function in infants with chronic pulmonary disease after severe adenoviral illness. J Pediatr 1999; 134: 730-3.

162.- THYS F, LIISTRO G, DOZIN O, MARION E, RODENSTEIN D. Determinants of FiO2 with oxygen supplementation during noninvasive two-level positive pressure ventilation. Eur Respir J 2002; 19 : 653-7.

163.- TIMOTHY B, OP'T H. "Physiology of Ventilatory Support”. En: Egan PD, Ed. Egan's Fundamentals of Respiratory Care 2003; 963-1002.

164.- TOUSSAINT M, CHATWIN M, SOUDON P. Mechanical ventilation in Duchenne patients with chronic respiratory insufficiency: clinical implications of 20 years published experience. Chron Respir Dis 2007; 4: 167-77.
165.- VAN AALDEREN W M, KRAAN J, KOETER G H, VAN DER SCHANS C P. Inspiratory muscle training in patients with cystic fibrosis. Respir Med 2001; 95: 31-6.

166.- VAN DEN BERG J W, SLEBOS D J, POSTMA DS, DIJKHUIZEN B, KOËTER G H, TIMENS W, et al. Feasibility of sputum induction in lung transplant recipients. Clin Transplant 2004; 18: 605-12.

167.- VEGA-BRICEÑO L E, ABARCA V K, SÁNCHEZ D I. Vacuna influenza en niños: estado del arte. Rev Chilena Infectol 2006; 23: 164-9.

168.- VEGA-BRICEÑO L E, GUIRALDES C E, SÁNCHEZ I. Cystic fibrosis: facing patient transition from the pediatrician to the internist. Rev Méd Chile 2006; 134: 365-71.

169.- VERLEDEN G M, VANAUDENAERDE B M, DUPONT L J, VAN RAEMDONCK D E. Azithromycin. Am J Respir Crit Care Med 2006; 174: 56670.

171.- VILARÓ J. Prueba de marcha de 6 minutos. En: Burgos F, Casan P. Manual SEPAR de Procedimientos, modulo 4. Barcelona, España: Publicaciones Permayer 2004, 100-14.

170.- VILCHEZ R A, DAUBER J, KUSNE S. Infectious etiology of bronchiolitis obliterans: the respiratory viruses connection-myth or reality?. Am J Transplant 2003; 3: 245-9.

171.- WAITCHES G M, STERN E J. High-resolution CT of peripheral airways diseases. Radiol Clin North Am 2002; 40: 21-9.

172.- WARD S, CHATWIN M, HEATHER S, SIMONDS A K. Randomised controlled trial of non-invasive ventilation (NIV) for nocturnal hypoventilation in neuromuscular and chest wall disease patients with daytime normocapnia. Thorax 2005; 60: 1019-24.

173.- WHITFORD H, WALTERS E H, LEVVEY B, KOTSIMBOS T, ORSIDA B, WARD C, et al. Addition of inhaled corticosteroids to systemic immunosuppression after lung transplantation: a double-blind, placebo-controlled trial. Transplantation 2002; 73 : 1793-9.

174.- WOHL M E, CHERNICK V. State of the art: bronchiolitis. Am Rev Resp Dis 1978; 118: 759-81.

175.- WRIGHT J L, CAGLE P, CHURG A, COLBY T V, MYERS J. Diseases of the small airways. Am Rev Respir Dis 1992; 146: 240-62.

176.- YALÇIN E, DOGRU D, HALILOGLU M, OZÇELIK U, KIPER N, GÖÇMEN A. Postinfectious bronchiolitis obliterans in children: clinical and radiological profile and prognostic factors. Respiration 2003; 70 : 371-5.

177.- YÁÑEZ L J, YUNGE M, EMILFORK M, LAPADULA M, ALCÁNTARA A, FERNÁNDEZ C, et al. A prospective, randomized, controlled trial of noninvasive ventilation in pediatric acute respiratory failure. Pediatr Crit Care Med 2008; 9: 484-9. 
178.- YATES B, MURPHY D M, FORREST I A, WARD C, RUTHERFORD R M, FISCHER A J, et al. Azithromycin reverses airflow obstruction in established bronchiolitis obliterans syndrome. Am J Respir Crit Care Med 2005; 172: 772-5.

179.- YOO Y, KIM D K, CHOI S H, KIM C K, KOH Y Y. Methacholine and adenosine 5'-monophosphate challenges in children with post-infectious bronchiolitis obliterans. Eur Respir J 2006; 27: 36-41.

180.- ZACK J, JACOBS C P, KEENAN P M, HARNEY K, WOODS E R, COLIN A A, et al. Perspectives of patients with cystic fibrosis on preventive counselling and transition to adult care. Pediatr Pulmonol 2003; 36: 376-83.

181.- ZENTENO D, PUPPO H, GONZÁLEZ R, KOGAN R. Test de Marcha de 6 minutos en Pediatría. Neumol Pediatr 2007; 2: 109-14.

182.- ZENTENO D, PUPPO H, GONZÁLEZ R, PAVON
D, VERA R, TORRES R, et al. Test de marcha de seis minutos en niños con bronquiolitis obliterante postviral. Correlación con espirometría. Rev Chil Enfer Respir 2008; 24: 15-9.

183.- ZENTENO D, PUPPO H, VERA R, TORRES R, CHUNG-YANG K, PRADO F, et al. Guías de rehabilitación para niños con enfermedades respiratorias crónicas. Neumol Pediatr 2008; 3 (supl 1): 25-33.

184.- ZHANG L, IRION K, KOZAKEWICH H, REID L, CAMARGO J J, DA SILVA PORTO N, et al. Clinical course of postinfectious bronchiolitis obliterans. Pediatr Pulmonol 2000; 29: 341-50.

185.- ZHANG L, MENDOZA-SASSI R A, WAINWRIGHT C, KLASSEN T P. Nebulized hypertonic saline solution for acute bronchiolitis in infants. Cochrane Database Syst Rev 2008; 8: CD006458.

186.- ZHANG L, SILVA F A. Bronchiolitis obliterans in children. J Pediatr (Rio J) 2000; 76: 185-92.

Correspondencia a:

Dr. Luis Enrique Vega-Briceño.

Pediatra Broncopulmonar. Hospital Padre Hurtado.

Departamento de Pediatría. Pontificia Universidad

Católica de Chile.

E-mail: levega@puc.cl 